\title{
EL VICIO Y LA AMBIVALENCIA NORMATIVA
}

\section{Emilio Lamo de Espinosa}

Universidad Complutense. Madrid

RESUMEN. Una larga tradición sociológica vincula orden social y orden normativo, desconociendo en qué inmensa medida el desorden moral forma parte de las instituciones sociales. Tomando como ejemplo máximo de desorden moral el vicio, y desarrollando el concepto mertoniano de ambivalencia normativa, este artículo trata de indagar la institucionalización social de la ambivalencia normativa. Tras analizar la conexión entre formas de matrimonio y formas de desviación sexual, se exponen las consecuencias sociales de la ambivalencia normativa: segregación de audiencias y doble vida, segregación espacial y tem. poral, incomunicación y lenguas marginadas. Finalmente se indaga el mecanismo sociopsicológico que fundamenta el vicio, a saber, la conexión entre transgresión moral y placer, fundándolo en el proceso histórico de domesticación del desorden catártico y racionalización de la vida cotidiana.

\section{UNA DEFINICION DEL VICIO; ILEGALIDAD, INMORALIDAD Y VICIO}

¿Qué es el vicio? $\mathrm{O}$ bien, ¿qué es un vicioso? $\mathrm{O}$, incluso, ¿es que tienen algo en común todos estos juegos aparte de la etiqueta que se le aplica? Pensamos que sí. De entrada, el vicio implica siempre una conducta degradada y denigrante, más que antisocial o meramente inmoral. Se trata de algo perverso, mórbido, repulsivo para cualquier conciencia honesta, algo cuya maldad e ignominia se impone por sí mismo sin necesidad de razonamiento 
y al margen de la mejor o peor educación. Es algo, pues, evidentemente reprobable y que todos saben que lo es.

Esta radicalidad del rechazo diferencia el vicio de la ilegalidad o la inmoralidad. Ilegal es aquella conducta que la sociedad así define en función de un código escrito y formalizado y de un procedimiento que ritualiza el código; ilegal es, pues, la conducta que, siendo violación del Derecho positivo, es, además, declarada como tal. Inmoral es la conducta que, violando un código de comportamiento usual, no escrito y generalmente aceptado, es declarada así; es decir, ha de haber violación de un código de conducta y declaración pública de tal violación. El Derecho positivo es válido para todos los súbditos de un Estado; el código moral, por el contrario, sólo para aquellos que lo aceptan. La evitación del vicio, por el contrario, es válida para todos - como el Derecho-, pero se impone por su propia evidencia y convencimiento - como la moral-. Esta repugnancia espontánea, típica de las actitudes racistas, encuentra aquí frecuentemente un nuevo campo de aplicación. La conducta del vicioso repugna espontáneamente y, como tal, produce el máximo de reacción social contraria, el máximo de reprobación. La conducta simplemente ilegal (mala quia probibita) produce una reacción mecánica, pero no evoca ninguna repugnancia; tampoco la conducta meramente inmoral (como mentir o robar) produce repugnancia, aunque, como conducta mala in se, dará lugar a sanciones sociales colectivas espontáneas. El vicio es algo más que la inmoralidad, un paso más en la degradación, y, así, no sólo da lugar a reprobación, sino a estigmatización y, eventualmente, a marginación. La misma estigmatización que sufre el negro o el judío, la misma repugnancia. La causa y el mecanismo son también semejantes: se rechaza violentamente aquello que se tiene más cerca.

Pues hay algo más, algo que, junto con la reprobación, constituye el núcleo de esta institución social: el vicio atrae, fascina y es un potente objeto del deseo. Matar, por ejemplo, no es, desde luego, un vicio; pero una persona que mata aviesamente y por placer, sin duda, es un vicioso. En todos los comportamientos a que hacíamos referencia, en todos aquellos que normalmente se subsumen bajo esta etiqueta, hay al menos este elemento: el comportamiento produce placer o satisfacción; es algo excitante, atrayente. Es decir, el comportamiento es un comportamiento expresivo, que se satisface a sí mismo y no busca nada más allá.

Cuando algo produce temor, miedo o incluso asco, y al mismo tiempo atrae y fascina, decimos que hay un sentimiento ambivalente. La ambivalencia del vicio va a ser, desde luego, su característica fundamental y la que va a ser más difícil de desentrañar. Pues la ambivalencia de los sentimientos se traduce socialmente en dualismo. El transgresor tiene que ocultarse; la transgresión debe ser secreta, y así el mundo del vicio se juega siempre en un claroscuro de publicidad y ocultamiento, secreto y escándalo, mundo en el que la murmuración en voz baja sirve al tiempo para revelar al culpable, 
pero también para informar de dónde o con quién se puede transgredir la norma. El relato en voz baja, contado en secreto, estigmatiza al transgresor, pero también lo hace objeto del deseo ajeno; fustiga su ignominia, pero excita al atento y ávido oyente; los detalles corroboran su execrabilidad, pero son también valiosos informes, y todo es un doble juego de máscaras sobre máscaras.

Se dirá que, a pesar de todo, la repugnancia que provoca el vicio no es irracional; que, por el contrario, los etbos colectivos no son sino acumulación secular de un saber pragmático sobre la buena vida, y que, en definitiva, el vicioso es rechazado porque se pierde irremisiblemente en el vicio. $Y$, así, no es vicioso el estudiante que una noche de farra acude al burdel; lo es, sin embargo, el que lo hace con tal asiduidad que sus economías, estudios o incluso salud se ven perjudicados. Es vicioso el avaro que acumula dinero por el mero placer de saber que lo tiene, pero no lo es quien trabaja compulsivamente para consumir más, pues el primero no contribuye a la sociedad, pero el segundo sí. Habría así otros elementos a añadir: la constancia o reiteración de la conducta, hasta el punto de que relega a un segundo plano toda otra consideración. Allí donde el sujeto se entrega al goce sin medida, hundiéndose en él, perdiéndose en ese «abismo de degradación» tal que ninguna reconvención o deber consigue controlarlo, estaríamos en el campo del vicio. El actor, como una máquina ciega, sustituye el vivir para (trabajar, cumplir sus deberes familiares, salvar su alma, etc.) por un vivir para el vicio. Hay, pues, un elemento de adicción a tal conducta, causa de su incapacidad para cumplir con sus deberes sociales.

Ahora bien, ¿qué ocurre, por ejemplo, en el caso de un médico de quien, súbitamente, se descubre que es un drogadicto y que lo ha sido durante varias décadas? ¿O del político conocido que de pronto se revela homosexual? Evidentemente, estos sujetos cumplían, incluso modélicamente, con sus deberes públicos. Sin embargo, la reacción social es la misma: tal sujeto es un vicioso que, arteramente, ha sabido ocultar su vicio. En tales casos funciona una memoria retrospectiva que reconstruye por completo la biografía e imagen pública de la personalidad del desafortunado, pillado con las manos en la masa, reconstrucción que, por así decir, es como una sensación de Eureka: ¡ahá!, así que, en el fondo, la familia y los hijos, la respetabilidad, etc., todo era un truco para ocultarnos su verdadero ser.

Pues el vicioso (como el negro o el judío) es alguien que está más allá de la culpa, la responsabilidad y la expiación. No cabe arrepentimiento, pues su pecado es ser como es. $\mathrm{Y}$, puesto que su vicio abarca toda su vida, no puede haber perdón para él. Siempre ha sido así y siempre lo será. No es su conducta lo que se recbaza, sino a él mismo, pues conducta desviada y personalidad son ahora socialmente idénticas. No hay un político padre de familia y homosexual, sino un homosexual disfrazado de político y padre de familia. No hay análisis que pueda separar lo intrínsecamente malo de él, 
pues su pecado es tan grande que todo él está manchado. El estigma es toda su identidad pública, que es radicalmente unidimensionalizada. Siempre y en todas partes estará pensando en lo mismo, «siendo» lo mismo, esencialmente. Pues lo importante no es lo que le pasa al actor, sino lo que la audiencia piensa lo que le pasa; lo importante -como casi siempre en sociologíano es la situación, sino la definición social de tal situación.

Así, pues, no es imprescindible el incumplimiento de los deberes sociales para que un sujeto sea calificado de vicioso. Es más, el vicioso controlado, que mide su adicción y la dosifica para evitar la publicidad y la reprobación social, es quizás peor que quien, dominado por un impulso irresistible, se pierde en el abismo. Este último ha sido fascinado por ese abismo y es, literalmente, un endemoniado, un poseído. De algún modo, no es él, sino un espíritu maligno, quien actúa a su través. El primero, por el contrario, es verdaderamente satánico: domina el mal, lo ejerce con conciencia y control, para así mejor ocultarlo y disfrutarlo. Aquí hay no sólo vicio, sino vicio agravado por la premeditación, el ocultamiento, la frialdad racional, en suma, con la que el sujeto sabe disfrutar sin que nada ni nadie sospeche.

La conducta viciosa es, pues, al tiempo modelo de lo que no debe hacerse nunca y modelo de lo que se desea hacer; es una conducta arquetípica y ambivalente. $Y$, por ello, a nadie sorprenderá que la reprobación social sea aquí mucho más fuerte que en el caso de conductas ilegales o inmorales. Primero, porque aquéllas no son expresivas $\mathrm{y}$, por lo tanto, la reprobación no se alimenta del deseo reprimido. En segundo lugar, el factor del secreto no actúa tan intensamente. Pues si la reprobación origina ocultamiento, éste, a su vez, alimenta la sospecha generalizada de que muchos (quizás todos), en secreto, practican la conducta prohibida. Esta sospecha le resulta insoportable al justo, que cree ver bajo sus pies un cáncer que todo lo corroe, y que el públicamente estigmatizado no hace sino testimoniar. El réprobo no es sino la punta de un iceberg oculto que en cualquier momento puede acabar con su equilibrio moral. $Y$, así, aquel que más desea la transgresión sospecha que muchos hacen en secreto lo que él también desearía hacer en secreto.

\section{EL TABU Y LA AMBIVALENCIA PSICOLOGICA}

A estas alturas, a casi nadie se le oculta que estamos apoyándonos tácitamente en el conocido texto de Freud Totem y tabú, publicado en 1913. De hecho, los caracteres que hemos asignado al vicio son los mismos que Freud atribuyó a la palabra tabú:

«Para nosotros - dice Freud- presenta el tabú dos significaciones opuestas: la de lo sagrado o consagrado y la de lo inquietante, peli- 
groso, prohibido o impuro. En polinesio lo contrario de tabú es noa, o sea lo ordinario, lo que es accesible a todo el mundo. El concepto de tabú entraña, pues, una idea de reserva y, en efecto, el tabú se manifiesta socialmente en prohibiciones y restricciones» ${ }^{1}$.

Existirían dos tipos fundamentales de tabú: el natural o directo, producto de una fuerza desconocida, y que lo poseen ciertos objetos o personas como si hubieran recibido una carga maléfica; el segundo tipo de tabú es el transmitido, y lo poseen quienes han entrado en contacto con algún tabú. Lo tabú se transmite y es contagioso, de modo que quien se aproxima a ello deviene el mismo tabú. La característica del tabú es, sin embargo, que

«se trata de una serie de limitaciones a las que se someten los pueblos primitivos, ignorando sus razones y sin preocuparse siquiera de investigarlas, pero considerándolas cosa natural y perfectamente convencidos de que su violación les atraería los peores castigos» ${ }^{2}$.

Freud se vio atraído hacia este tema por estimar que «la esencia de las prohibiciones tradicionales y éticas a las que, por nuestra parte, obedecemos pudiera poseer una cierta afinidad con este tabú primitivo, de manera que el esclarecimiento del mismo habría quizás de proyectar alguna luz sobre el oscuro origen de nuestro propio imperativo categórico" ${ }^{3}$, formando incluso «la raíz de nuestras prescripciones morales y de nuestras leyes» ${ }^{4}$. Además, le interesaban a Freud una serie de analogías que creía observar entre el tabú y las neurosis obsesivas:

«la primera y más evidente analogía que con el tabú presentan estas prohibiciones obsesivas (en los neuróticos) es la carencia de toda motivación y el enigma de sus orígenes. Surgieron repentinamente un día y desde entonces se ve obligado el sujeto a observarlas bajo la coerción de una irreprimible angustia» ${ }^{5}$.

Pero, sin duda, la característica más relevante de esta analogía es lo que (en expresión de Bleuler) Freud denominó «actitud ambivalente del sujeto con respecto al objeto o, más bien, el acto prohibido». Pues al tiempo que «experimenta de continuo el deseo de realizar dicho acto - el toçamientole retiene siempre el honor que el mismo le inspira». Y «mientras que la prohibición es claramente consciente, la tendencia prohibida, que perdura, insatisfecha, es por completo inconsciente y el sujeto la desconoce en abso-

'S. Freud, Totem y tabú (Alianza Editorial, Madrid), 1967, p. 29.

Ibidem, p. 33.

${ }^{3}$ Ibidem, p. 35 .

4 Ibidem, p. 37.

${ }^{5}$ Ibidem, p. 40. 
luto» ${ }^{6}$. Por ello, el hombre que ha violado un tabú se hace tabú a su vez, porque «posee la facultad peligrosa de incitar a los demás a seguir su ejemplo». Resulta, pues, realmente contagioso. Esto le permitió a Freud descubrir el mecanismo psíquico del desplazamiento:

"Cuando un individuo ha conseguido satisfacer un deseo reprimido, todos los demás miembros de la colectividad deben de experimentar la tentación de hacer otro tanto; para reprimir esta tentación es necesario castigar la audacia de aquel cuya satisfacción se envidia, y sucede, además, con frecuencia que el castigo mismo proporciona a los que lo imponen la ocasión de cometer a su vez, bajo el descubrimiento de la expiación, el mismo acto impuro. Es éste uno de los principios fundamentales del orden penal humano y se deriva, naturalmente, de la identidad de los deseos reprimidos en el criminal y en aquellos que se hallan encargados de vengar a la sociedad ultrajada» ${ }^{7}$.

De modo que el castigo no sólo restablece el orden violado, pues sirve también de vía de escape para los deseos reprimidos y activados por la transgresión. Mecanismo que pocos años antes había sido ya analizado en términos casi idénticos por Durkheim, también en el contexto de la sanción penal: «la verdadera función [de la pena] es mantener intacta la cohesión social, manteniendo en toda su vitalidad la conciencia común». Por ello,

«se puede decir sin incurrir en paradoja que el castigo está destinado sobre todo a actuar sobre las personas honestas ${ }^{8}$.

Pues, de no ser así, no se entiende «qué necesidad habría de prohibir lo que nadie desea realizar; [de modo que] aquello que se halla severamente prohibido tiene que ser objeto de un deseo» ${ }^{9}$.

Encontramos, pues, toda una serie de analogías entre el tabú y el vicio, que pueden resumirse de este modo:

1. Evidencia de la prohibición.

2. La ambivalencia, es decir, el deseo de transgresión reprimido.

3. El contagio de la impureza.

4. El castigo del culpable como afirmación simbólica del orden violado y, al tiempo, canalización del deseo reprimido y activado por la violación.

- Ibidem, p. 44.

Ibidem, p. 99.

\& Emile Durk herm, De la division du travail social (PUF, París), 1967, pp. 76 y 77.

9 S. Freud, op. cil., p. 95. 
Esta analogia entre la conciencia tabú y el vicio nos hace ver que estamos ante una forma primitiva de moralidad, cuya característica básica es que «no tiene necesidad de invocar razones ningunas y posee una plena seguridad de sí misma» ${ }^{10}$, seguridad que las transgresiones y violaciones visibles no hacen sino confirmar. Efectivamente, la transgresión provoca en el justo un horror inmenso y estpontáneo que no es sino proyección agresiva de su deseo reprimido. Por ello, tanto más violenta será la reacción social contra el transgresor cuanto mayor sea la fuerza del deseo oculto y cuanto más consciente y menos reprimido esté. Pues es precisamente entonces, cuando el deseo se hace patente y el justo descubre con horror que él también participa de la ignominia, cuando más violenta debe ser su respuesta.

Esta ambivalencia psíquica puede alterar de modo importante una de las tesis claves de la sociología penal de Durkheim: «un acto es criminal cuando ofende los estados fuertes y definidos de la conciencia colectiva» ". Pues el juego de la ambivalencia hace que la reacción social pueda extraer su fuerza parasitando la del deseo, de modo que la sociedad reaccionará violentamente cuando el sentimiento ha dejado de ser común, y como único modo de reafirmarlo no ya sólo cara a los otros, sino sobre todo cara a uno mismo. Podría ocurrir entonces que la violencia de la reacción social penal fuera un indicador no de la aceptación de ese tipo de conciencia moral, sino precisamente del desvanecimiento de la conciencia colectiva, que daría lugar a un agravamiento de las sanciones. En definitiva, cuando más necesario es afirmar públicamente un principio es cuando está dejando de ser aceptado. Entonces su afirmación pública sustituye simbólicamente a su negación real y efectiva y se reafirma simbólicamente lo que se niega en la práctica.

En estos casos, no es la inconsciencia del deseo, sino más bien su relativa consciencia, lo que alimenta la venganza penal. Todo ocurre como si las cosas se bicieran aunque sobre ellas nada se podría decir, pues lo relevante es no la conducta, sino el conocimiento público de esa conducta, que es ahora delictiva o inmoral (especialmente esto último) cuando es públicamente afirmada e incluso defendida, pues no es la práctica lo que se preserva, sino sólo el reconocimiento. En estas condiciones de hipocresía social institucionalizada, lo importante no es lo que los sujetos hacen, sino lo que públicamente se sabe que hacen, pues no ataca a la moral dominante su violación secreta, sino su negación pública.

${ }^{10} \mathrm{~S}$. FREUd, ibidem, p. 94.

"E. Durk h eim, op. cit., p. 47. 


\section{LA AMBIVALENCIA SOCIOLOGICA Y LA INSTITUCIONALIZACION DE LA HIPOCRESIA}

Así, en un sistema moral de bipocresía institucionalizada, no se trata de preservar la pureza de las conductas, sino sólo la de las opiniones, y la reacción no se desata contra las violaciones realizadas con discreción (concepto clave en este contexto, que muestra que incluso la violación de la norma puede ser alabada si se hace adecuadamente), sino contra el exbibicionismo de la conducta inmoral, es decir, contra la defensa pública de la inmoralidad. La sociedad funciona entonces con una conciencia escindida: acepta -incluso alaba veladamente - al transgresor discreto, mientras sanciona al mero defensor público de la transgresión. Estamos ya en el terreno de las opiniones y no tanto en el de las conductas.

Esta institucionalización de la hipocresía se produce cuando la sociedad pierde la ingenuidad espontánea de la conciencia moral primitiva y en su lugar aparece la dual ${ }^{12}$. La estrategia de salvar las apariencias tiene así una doble función. Permite alterar la práctica sin alterar paralelamente el código moral, con el consiguiente efecto de desgaste y deslegitimación que ello produciría, y permite que las violaciones no se difundan excesivamente y sean, por así decirlo, experimentadas antes de ser públicamente rechazadas o aceptadas ${ }^{13}$.

Por otro lado, esta situación, en principio transitoria, puede cronificarse por estas mismas dos razones. Permite que los monopolizadores o empresarios de la moral pública ${ }^{14}$ conserven el control de ésta sin alterar un ápice sus mandatos y consejos. Permite también que sólo una minoría (concretamente aquellos que por disponer de privacidad pueden controlar la publicidad de sus actos) tenga acceso al mercado del vicio. $Y$ mientras un grupo trata de conservar el monopolio de los interdictos, otro conserva el monopolio de las transgresiones.

12 Requisito para ello es también la ruptura de la comunidad integrada rural para dar lugar a una diversidad de clases y grupos sociales, por un lado, y un fuerte enclaustramiento social de los diversos grupos. Esta atomización es requisito para poder segregar contextos sociales, tal que cada uno no sepa lo que pasa en otro. En definitiva, el secreto sólo puede existir allí donde la disociación entre vida privada y vida pública es máxima. Pero la privacidad es un fenómeno típicamente urbano, igual que el mantenimiento de relaciones sociales segmentadas. Véase $\mathrm{L}$. WIRT $\mathrm{H}$, «Urbanism as a Way of Life», American Journal of Sociology, 44 (1938), pp. 1-24.

${ }_{13}$ Esta idea de la experimentación de formas de vida, como consecuencia del posible secreto de las transgresiones normativas (secreto que sólo es posible en el supuesto del máximo respeto a la privacidad), es uno de los puntos centrales del liberalismo de J. Sruart Mill: véase Sobre la libertad (Alianza Editorial, Madrid), 1970.

${ }_{14}$ El concepto de empresarios de la moral procede de la obra de Howard BecKer, Los «otros» entre nosotros (Sagitario, Barcelona), 1966. Con ello alude a aquellos actores sociales (individuales o colectivos, como, por ejemplo, una Iglesia) a quienes se les ha atribuido (por cualesquiera razones) la misión de velar por la defensa (lo que incluye, por supuesto, la definición y el mantenimiento) de una moral pública (entendida ésta no en cuanto moral positiva, sino como moral dominante). 
Ahora bien, lo que más directamente nos interesa es esta institucionalización social de la «doble moral». Pues el fenómeno de la ambivalencia, desde Blauer, ha sido analizado en términos psíquicos únicamente. Es más, de los tres tipos de ambivalencia señalados por Bleuler (la emocional, la cognitiva y la conativa), sólo las dos primeras han recibido atención suficiente (con Freud y con la teoría de la disonancia cognitiva, respectivamente). Ahora bien, como dice R. K. Merton,

«a diferencia de la orientación psicológica, la sociológica se interesa por los modos en que la ambivalencia es construida en la estructura de status y roles sociales. Nos orienta a examinar los procesos en la estructura social que afectan a la probabilidad de que la ambivalencia surja en tipos particulares de relaciones de rol. Y, por último, nos orienta hacia las consecuencias sociales de la ambivalencia en el funcionamiento de las estructuras sociales» ${ }^{15}$.

El concepto de ambivalencia sociológica resulta mucho más adecuado que el de ambivalencia psíquica afectiva por cuanto, a diferencia del caso del tabú, estamos hablando de deseos que son, en general, conscientes o semiconscientes, tanto que forman parte de las expectativas normales de muchos individuos que ocupan roles específicos. $\mathrm{Y}$ éste es, según Merton, el núcleo de la ambivalencia sociológica:

«la teoría sociológica trata de los procesos a través de los cuales las estructuras sociales generan las circunstancias en las que la ambivalencia está incorporada en status o conjuntos de status junto con sus roles sociales asociados» ${ }^{16}$.

En su sentido más restringido alude a expectativas normativas en conflicto, socialmente definidas para un rol particular asociado a un status concreto" ${ }^{17}$, ya que en estos casos la sociedad impone deberes contradictorios $y$, puesto que tales deberes no pueden cumplirse simultáneamente, surge una típica «oscilación de comportamientos». Desde esta perspectiva, un rol no debe concebirse como un conjunto unificado de normas, «sino como una organización dinámica de normas y contranormas», que alternativamente controlan la conducta. La aportación de Merton extiende, pues, los análisis, ya conocidos, acerca de las evasiones institucionalizadas y pautadas de las normas ${ }^{18}$ para hacer de ello no una excepción, sino una verdadera teoría general.

${ }^{15}$ Robert K. Merton y Elinor Barber, «Sociological Ambivalence», en R. K. MERToN, Sociological Ambivalence (The Free Press, Nueva York), 1976, p. 5.

${ }_{16}$ Ibidem, p. 7.

17 Ibidem, p. 8.

${ }_{18}$ Véase Robin WILLIams, American Society: A Sociological Interpretation (Alfred A. Knoph Inc., Nueva York), 1960, cap. 10. 
Merton ha elaborado un catálogo de distintos tipos de ambivalencia sociológica, señalando los siguientes:

1. conflicto de roles de un status;

2. conflicto de status de un status-set;

3. conflicto cultural entre distintos fines o metas dentro de una misma cultura;

4. conflicto cultural entre fines y medios, es decir, entre una cultura $y$ una estructura social ${ }^{19}$;

5. conflicto entre culturas distintas a que pueden verse sometidos aquellos individuos (emigrantes, por ejemplo) que pertenecen a ambas.

Con tal clasificación, Merton está detallando todos aquellos casos en que una persona se ve sometida a presiones contradictorias, bien entre dos normas morales, bien entre una norma y su imposible cumplimiento. A este último - y peculiar - caso corresponde el definido con el número 4; es un supuesto atípico, pues el actor no tiene que vérselas con dos normas contradictorias, sino únicamente con la imposibilidad de cumplir la única que sería aplicable.

Por ello, la ambivalencia sociológica propiamente dicha sólo comenzaría en los casos de conflicto normativo y no estructural, es decir, cuando un actor se ve moralmente impulsado a actuar de modo contradictorio. Ahora bien, en tales supuestos debe también distinguirse si la contradicción deriva del cruce entre dos códigos éticos independientes (caso del conflicto cultural, número 5) o de dos normas de un mismo código (supuestos 1,2 y 3). Sólo en este último caso puede hablarse con propiedad de ambivalencia sociológica: un mismo código moral impondría pautas no conciliables de conducta.

Podría pensarse que tales supuestos constituyen la excepción, apareciendo únicamente en los márgenes de los códigos morales o en raras instancias de conflicto normativo. Creo, por el contrario, que la insistencia (de moralistas primero y funcionalistas después) en la unidad moral de la cultura occidental y, dentro de ella, de cada cultura o subcultura, nos hace olvidar frecuentemente en qué inmensa medida este orden, aparentemente uniforme, está traspasado de contradicciones, cortes, rupturas y negaciones. Quizás nadie como Margaret Mead ha sabido ver esta profunda diversidad cultural, evidente sólo para quien, desde la variedad antropológica, analiza su propia sociedad:

«Nuestros jóvenes confrontan una serie de grupos diferentes que creen en cosas diferentes y defienden prácticas diferentes y a los cuales pue-

19 Con ello, la conocida teoría mertoniana de la anomia, expuesta en Teoría y estructura sociales (FCE, México), 1964, caps. IV y V, como resultante de la contradicción existente entre fines culturalmente establecidos y los medios legales para alcanzarlos, no sería sino un caso especial de la ambivalencia sociológica. 
de pertenecer algún pariente o amigo de confianza. Así, el padre de una chica podría ser un presbiteriano, imperialista, vegetariano, abstemio, con una fuerte preferencia literaria por Edmund Burke, que cree en la libertad de comercio y la protección aduanera, estima que el lugar de la mujer es la casa, que las jovencitas deben llevar corsé, no deben enrollar sus medias, no deben fumar ni salir con chicos por la noche. Pero el padre de su madre puede ser un episcopaliano de los Derechos de los Estados y la Doctrina Monroe, que lee a Rabelais y gusta de ir a los conciertos y las carreras de caballos. Su tía es agnóstica, enérgica defensora de los derechos de las mujeres, internacionalista, basa toda su esperanza en el Esperanto, adora a Bernard Shaw y dedica su tiempo libre a campañas contra la vivisección. Su hermano mayor, a quien admira extraordinariamente, acaba de pasar dos años en Oxford. Es un anglo-católico entusiasta de todo lo medieval, escribe poesía mística, lee a Chesterton y piensa dedicar su vida a buscar el secreto perdido del cristal emplomado medieval. El hermano más joven de su madre es un ingeniero, materialista rígido que nunca se recuperó de la lectura de Haeckel que hizo en su juventud; desprecia el arte, cree que la ciencia salvará el mundo, se ríe de todo lo que se dijo y pensó antes del siglo XIx y estropea su salud experimentando con la supresión científica del sueño. Su madre tiene un tono espiritual quietista, está muy interesada en la filosofía india, es pacifísta, una estricta no-participante en la vida y, a pesar de la devoción que su hija siente por ella, no hará nada para movilizar ese entusiasmo. Y esto puede ocurrir en el propio hogar de esta chica. Añadir a ello los grupos representados y defendidos por sus amigos, maestros y los libros que lee accidentalmente, de tal modo que la lista de entusiasmos posibles y compromisos sugestivos, incompatibles unos con otros, es abrumadora ${ }^{20}$.

Esta gigantesca diversidad cultural, que se manifiesta muy especialmente en el terreno moral, tiene también su plasmación en todo lo relativo a pautas de conducta sexual. Kinsey resumió del modo siguiente sus conclusiones:

«Los datos de que disponemos muestran que las pautas de conducta sexual pueden ser asombrosamente diferentes en los distintos niveles sociales que existen en la misma ciudad o pueblo, y a veces en secciones inmediatamente adyacentes de la misma comunidad... Las divergencias en las pautas sexuales de tales grupos sociales pueden ser tan grandes como las que los antropólogos han encontrado entre las pautas sexuales de grupos raciales distintos en lugares remotos del mundo» ${ }^{21}$

${ }^{20}$ M. Mead, Coming of Age in Samoa (Nueva York), 1928, pp. 202-203.

${ }^{21}$ Citado por H. J. EysencK, «Normality, Sex and Social Class», en Uses and Abuses 
Pues bien, esta enorme variabilidad, generadora de ambivalencia, nos interesa por cuanto muchas de las conductas viciosas a que estamos haciendo referencia pueden ser resultado de expectativas contradictorias. Y ello en un doble sentido: bien porque el actor se encuntra sometido a dos o más códigos contradictorios, bien porque hay contranormas que exigen de él conductas prohibidas por otras normas.

En tales supuestos, las alternativas del actor son complejas, pero conllevan siempre alguna transgresión. Efectivamente, sea cual sea el supuesto de conflicto normativo, está condenado a seguir una de las tres siguientes líneas de acción:

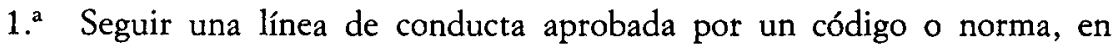
detrimento y violación de lo establecido en otro código o norma, que a partir de ese momento es rechazado.

2. ${ }^{a} \quad$ Elaborar una transacción o vía intermedia entre ambas normas. De entre las muchas posibles transacciones es evidente que la inacción (la retirada; en última instancia, el suicidio) es una de las más importantes.

3. Finalmente, el actor puede seguir una conducta oscilante, respetando en ciertos tiempos y lugares, y ante ciertas audiencias, unas normas, y respetando otras en otros tiempos y lugares y ante distintas audiencias. Es este último supuesto el que más va a interesarnos como guía para analizar la institucionalización de la hipocresía a que aludíamos anteriormente. Pero antes pondremos algunos ejemplos de ambivalencia normativa.

No hace mucho que Margarita Nelken aludía «al donjuanismo chulesco que tanto impera entre el pueblo de las capitales» y considera como acto de bravura «hacerle una barriga» a una muchacha. Todavía hoy es rito de iniciación para los varones acostarse con una mujer, al tiempo que a éstas se les impone la virginidad y la prostitución es moralmente rechazada. El mismo carácter iniciático tiene probar la droga en la subcultura juvenil. Margarita Nelken ofrecía otros ejemplos:

«que gran culpa debe recaer sobre la falsa idea del honor en el pueblo que hace considerar honroso para la familia una cocotte o soi-disant artista con automóvil y que impone como un deber sagrado el echar del hogar a puntapiés a la hija abandonada; que gran culpa también debe recaer sobre las asociaciones benéficas que en lugar de ayudar más, por necesitarlo más, a la madre sin marido, la rechazan hacia la Inclusa y la mala vida, a veces hacia el infanticidio» ${ }^{22}$.

of Psychology (Penguin Books, Baltimore), 1966, p. 184. Eysenck muestra esa variedad de pautas por clases sociales, con datos extraídos del trabajo de Kinsey.

${ }_{22}$ M. Nelken, La condición de la mujer en España (Editorial Minerva, S. A., Barcelona), s.d. (circa 1920), p. 143 . 
Igualmente, la prostitución deriva (por el lado de la oferta) de la norma que impone la virginidad y de la imposibilidad de encontrar trabajo alternativo, o el aborto (o el infanticidio) de la norma que impone la honestidad a la mujer soltera, etc.

En definitiva, la ambivalencia sociológica no es sino una descripción neutra de lo que antes denominábamos hipocresía institucionalizada, enfocada en términos estructurales y no sólo psicológicos.

Ahora bien, lo que Merton no ha llegado a desarrollar es la amplia gama de consecuencias que se derivan de esta teoría cuando se aplica al campo de la desviación social. Analicemos con detenimiento el caso de las conductas sexuales inmorales $y / o$ desviadas.

\section{PROSTITUCION Y ECONOMIA SEXUAL}

¿Cuáles son las causas de la prostitución? Lo usual ha venido siendo atribuirla a las normas morales represivas que controlan la libertad de las relaciones sexuales. Ya Mandeville, en su Fable of the Bees, Private Vices, Public Benefits (1714), afirmaba: «Es evidente que existe la necesidad de sacrificar a una parte de las mujeres para conservar la otra y prevenir una suciedad de naturaleza mucho peor.» Desde entonces, la literatura socialista y feminista (Bebel, Rosa Luxemburgo, Clara Zetkin o W. Reich) ha venido repitiendo lo mismo: "la existencia de una casta de "hijas perdidas" permite tratar a la "mujer honesta" con el respeto más caballeresco" ${ }^{23}$. Tampoco la sociología ha avanzado mucho en este terreno, y las causas a que $\mathrm{K}$. Davis atribuía la prostitución en un trabajo clásico son, en gran medida, una mera especificación de lo anterior:

«En resumen, el intento, por parte de la sociedad, de controlar la expresión sexual, de atarla a sus exigencias sociales, especialmente el intento de atarla a una relación matrimonial duradera y a la crianza de los hijos, o de condenar a los hombres al celibato, o de fundar la expresión sexual en el amor, todo ello crea la oportunidad de la prostitución. Es así análoga al mercado negro, respuesta ilegal pero inevitable del intento de controlar totalmente la economía» ${ }^{24}$.

Resulta difícil negar la veracidad de tales afirmaciones. Pero creemos que es necesario ampliar el marco analítico si queremos dar cuenta de la actual existencia e incluso crecimiento de la prostitución. Pues si todo se redujera a ser el reverso del matrimonio, habría que concluir -como hace Davis-

${ }^{23}$ Simone DE Beauvoir, El segundo sexo (Siglo Veinte, Buenos Aires), 1970, vol. II, p. 339; Auguste BEBEL, La mujer (Ediciones Júcar, Madrid), 1980.

${ }^{24}$ K. Davis, «Prostitución», en R. Nisbet y R. K. Merton (eds.), Contemporary Social Problems (Harcourt Brace and World Inc., Nueva York), 1961, p. 275. 
que con «la mayor disponibilidad de mujeres ordinarias para compañía sexual... el papel de la prostituta, tanto en volumen como en status, declinará», y así «la decadencia de la familia tradicional y de la prostitución están ambas asociadas con un alza de la libertad sexual» ${ }^{25}$.

Davis cita en su apoyo datos extraídos del Informe Kinsey que muestran que la relación con prostitutas en la generación joven era entre la mitad y un tercio de la de generaciones anteriores. Esto es innegable, pero no lo es tanto que la prostitución haya disminuido; y en muchos sitios no sólo no disminuye, sino que aumenta, al tiempo que lo hace la permisividad sexual. Inversamente, y como muestra Ivan Light, la prostitución, que fue la gran industria ilegal en Estados Unidos durante el xIx, comenzó a decaer a comienzos de siglo, sin que ello pueda atribuirse a ningún cambio en la moral colectiva, sino más bien al equilibrio progresivo de la relación entre ambos sexos (consecuencia del cambio de la Ley de Inmigración de 1924) y el consecuente aumento de la tasa de población casada ${ }^{26}$. Mientras que existió un volumen importante de varones solteros en los EE. UU., la demanda de relaciones sexuales comerciales se mantuvo ${ }^{27}$.

¿A qué se debe entonces la prostitución? En las siguientes páginas encuadramos esta forma de desviación sexual en un análisis más amplio de la demanda de desviación sexual en general, por una parte, y de la oferta de prostitución, por otra. Veremos cómo es la sociedad la que canaliza las pulsiones sexuales en uno u otro sentido, generando así demanda por una $u$ otra forma de satisfacer tales pulsiones. Es igualmente la sociedad la que genera en ocasiones y lugares específicos la oferta que, eventualmente, cubre tal demanda.

\subsection{La demanda de desviación sexual}

Todos sabemos que nacen más hombres que mujeres, aproximadamente 105 varones por cada 100 mujeres, pero que la mayor mortalidad infantil de los primeros equilibra los sexos al final de la pubertad. De ahí la suposición espontánea de que, puesto que hay paridad de sexos, habría también, al menos, un compañero sexual para cada hombre y mujer. Sin embargo,

«de modo similar a lo que ocurre con la competencia perfecta en un sistema económico, la realización de una competencia perfecta entre miembros de un sexo para encontrar compañeros del sexo opuesto es sistemáticamente impedida por fuerzas presentes en la estructura de la mayoría de las sociedades» ${ }^{28}$.

25 Ibidem, p. 288.

${ }^{26}$ Ivan Lighr, The Ethnic Vice Industry, op. cit., p. 68.

${ }^{27}$ N. Polsky, Hustlers, Beats and Otbers (Doubleday, Nueva York), 1969, p. 21.

${ }^{28}$ A. E. ANSWORTh y W. M. W ALKER, «Social Structure and Homosexuality", The British Journal of Sociology, 2 (1972), pp. 146 y ss. 
Así, por poner un ejemplo conocido: la poligamia de los países islámicos está sólo al alcance de una minoría de varones económicamente poderosos ${ }^{29}$. La consecuencia evidente de tal poligamia es condenar a un cierto número de varones a la castidad, la homosexualidad o al burdel (allí donde lo hay). Por ello, los autores citados, en un sugestivo artículo, proponen la siguiente hipótesis:

«Si en una sociedad o en algún grupo de esa sociedad el acceso de los miembros de un sexo a miembros del sexo opuesto con objetivos matrimoniales, eróticos o de simple compañía, es obstruido persistentemente por características de la estructura social, se producirá entonces una tendencia en las colectividades implicadas hacia una alta incidencia de conducta homosexual y una actitud relativamente tolerante hacia la misma. En resumen, surgirá una bomosexualidad institucionalizada» ${ }^{30}$.

Una tesis similar fue sugerida ya hace tiempo en relación con la tolerancia hacia la homosexualidad en los países musulmanes ${ }^{31} \mathrm{y}$, posteriormente, en la alta incidencia del lesbianismo entre profesionales del strip-tease ${ }^{32}$. En este último caso, la no accesibilidad derivaría no del desequilibrio demográfico (accesibilidad física), sino del bajo status social de tales mujeres (accesibilidad social), y ha sido generalizada por los autores citados a la homosexualidad del mundo de los cómicos y del espectáculo londinense.

Lo que esta tesis sugiere es que un modelo más general, válido no sólo para la homosexualidad, sino también para otros fenómenos desviados como la prostitución, el incesto, adulterio o masturbación, debe tener en cuenta un marco de referencia más amplio: el constituido por los diversos modos de canalizar las pulsiones sexuales. A tal efecto, es posible concebir las normas relativas al matrimonio y las relaciones sexuales en general como una canalización social de las pulsiones sexuales individuales que pueden trasladarse de las relaciones legítimas a las ilegítimas (o viceversa) en función de las posibilidades efectivas de encontrar consumación.

La prostitución, como el matrimonio, la homosexualidad, etc., serían así modos alternativos de dar satisfacción a tales pulsiones. Un marco aún más amplio (más relevante para la antropología comparada que para la sociología) debiera tomar en consideración, también, las relaciones entre erotismo y genitalización (o sexualidad) en el sentido indicado, por ejemplo, por Marcuse; en qué medida una cultura sexualiza o no la más difusa pulsión erótica es una variable a analizar en función de factores tales como la construcción so-

${ }^{29}$ Véase G. P. Murdock, Social Structure (The Free Press, Nueva York), 1965, p. 27.

${ }^{30}$ ANSWORTH y WALKER, op. cit., p. 148. (La cursiva es nuestra.) p. 18.

S. ANDRZEJEwSKI, Military Organization and Society (Routledge, Londres), 1954,

${ }^{32}$ C. H. McCaghy y J. K. Skipper, «Lesbian Behaviour as an Adaptation to the Occupation of Stripping», Social Problems, 17, 2 (1969), p. 262. 
cial del cuerpo masculino y femenino, el trabajo, las relaciones familiares y edípicas, etc.

Vamos a dejar de lado este marco de referencia más amplio para limitarnos al estudio de la canalización social de la pulsión sexual. Supondremos, pues que esta última es constante.

Pues bien, en tales condiciones, para que la pulsión sexual de todos y cada uno de los sujetos de una sociedad pueda encontrar satisfacción en el marco de una unión estable y monógama, es necesario - desde el punto de vista estructural - que ocurra todo lo siguiente:

a) Que haya equilibrio demográfico entre los sexos, es decir, igual número de hombres o mujeres; un desequilibrio obligará a un hombre a tener varias mujeres o a una mujer varios hombres, salvo que renuncien a la monogamia o recurran a la homosexualidad (masculina o femenina); por lo tanto, es necesario que haya al menos un hombre para cada mujer y al menos una mujer para cada hombre.

b) Accesibilidad social, es decir, libertad de relación, pues las normas que, para grupos específicos, regulan los matrimonios permitidos, prohibidos u obligatorios pueden hacer que, aun cuando para la sociedad globalmente considerada haya equilibrio demográfico, para algún grupo específico (normalmente los que ocupan la cima y la base de la estratificación social) exista desequilibrio; fenómenos sociales como la guerra, la emigración o las reglas de herencia favorecen estos fenómenos ${ }^{33}$. Así, pues, no sólo es necesario que haya un hombre para cada mujer, y viceversa, sino también que tengan acceso social libre los unos en relación con los otros.

Ello significa que, allí donde está institucionalizada la monogamia, los desequilibrios (sean naturales, sean sociales) no pueden ser solucionados a través de la poligamia o la poliandria; la consecuencia es una condena a la soltería perpetua, bien a los hombres, si hay falta de mujeres, o a éstas, si hay déficit de hombres.

c) Es necesario también que estas posibilidades de acceso sean efectivas tan pronto como aparece la pulsión sexual con la adolescencia; en caso contrario habrá de nuevo desequilibrios. Así, la norma moral que autoriza e impulsa a los varones adolescentes a tener aventuras sexuales, negando ese derecho a las adolescentes, origina una demanda de prostitución (o de adulterio) por parte de esos varones vírgenes forzosos; igualmente, posponer la

${ }^{33} \mathrm{U}$ otros, como podría ser el infanticidio femenino, practicado por algunos pueblos primitivos. Así, los todas, que debido a su tipo de cultura no necesitan del trabajo femenino; las mujeres son entonces una carga social $\mathrm{y}$, así, practican el infanticidio femenino, lo que desequilibra la relación entre los sexos y fuerza a relaciones poliándricas - véase W. H. R. Rivers, The Todas (Londres), 1906, pp. 477-480-. Así, en relación con la poliandria, G. P. Murdock afirma lo siguiente: «A pesar de lo limitado de los casos (conocidos), parece haber razones para asumir que la poliandria puede a veces ser debida a la escasez de mujeres debido al infanticidio femenino» (Social Structure, op. cit., p. 25). 
edad del matrimonio hasta bien entrados los veinte (como ocurría en la España de posguerra por razones económicas), allí donde las relaciones prematrimoniales están prohibidas, origina de nuevo demanda de prostitución. Por lo demás, bien sabido es el sustituto adolescente ante la prohibición de entablar relaciones sexuales prematrimoniales, la imposibilidad de contraer matrimonio y la ausencia de dinero para acudir al burdel: la masturbación.

d) Finalmente, las normas morales que regulan la decencia en las relaciones sexuales matrimoniales, en relación con los deseos de los cónyuges; un desequilibrio entre los deseos y su eventual satisfacción intramatrimonial generará pulsiones que sólo extramatrimonialmente podrán satisfacerse.

Resumiendo, la satisfacción heterosexual y monógama de la pulsión sexual exige que baya mujeres (o hombres), que se tenga acceso legítimo a ellas (o ellos) y que satisfagan (ellas o ellos).

Inversamente, bajo condiciones de monogamia institucional y de desequilibrio (demográfico o social) entre los sexos, se produce un porcentaje de personas condenadas a la soltería y la castidad, a las cuales sólo les quedarían abiertas las siguientes formas de desviación alternativas:

1. La bomosexualidad (masculina o femenina), modo de dar salida a las pulsiones sexuales de forma que se reequilibra la relación entre los sexos. Accidentalmente, esta respuesta se puede producir (y se produce) con carácter temporal cuando, por cualquier causa, personas de un mismo sexo son forzadas a convivir cotidianamente (así, la típica homosexualidad de internados, prisiones, cuarteles o buques); lo que prueba que, contra una creencia común, la homosexualidad es sustituto funcional de la heterosexualidad, dadas ciertas condiciones ${ }^{34}$.

2. Las relaciones incestuosas o adulterinas, como solución de las estrictas normas de exogamia o acceso, imposibles de cumplir; de este modo, el (o la) soltero(a) forzoso(a) da salida a sus pulsiones parasitando la familia ajena o la propia en una relación de poligamia (o poliandria) encubierta. Así, la mujer condenada a la soltería, y a través de las relaciones adúlteras, puede satisfacer sus pulsiones sexuales; como carece de marido y es posible que carezca también de patrimonio propio ${ }^{35}$ y/o de trabajo, aceptará del

${ }^{34}$ El lenguaje carcelario distingue claramente entre el homosexual circunstancial (bujarron, si es activo; niño, si es pasivo) y el que ingresa ya siéndolo (madre, madraza, carroza; fag, en Estados Unidos). Véase J. J. Caballero, «Sentido de la homosexualidad en la prisión», Cuadernos de Politica Criminal, 9 (1979), p. 121. Sobre la homosexualidad en la sociedad de frontera norteamericana, donde se sufrió un déficit crónico de mujeres, véase Frank ScarpitTr, Social Problems (Holt, Rinehart and Winston, Nueva York), 1974 , p. 445.

${ }_{35}$ Pero no siempre ocurre así; es frecuente en el medio rural que el continuo déficit de varones (como consecuencia de la emigración o por ser marinos, como ocurría en Galicia y algunas de las islas Baleares) obligue al establecimiento de un sistema matriarcal; en este caso, el patrimonio se hereda por la línea femenina y así se evita la prostitución 
amante regalos o dones que éste libremente quiera hacerle, para poder atender sus necesidades y las de su prole. Así, la soltera se ve forzada a parasitar otra familia para mantener la suya, en una relación intermedia entre la poligamia (lo sería si pudiera casarse con su amante) y la prostitución (lo sería si concediera sus favores a cualquier hombre). Por la misma razón, un varón condenado a la soltería (como lo era el secundón de alto linaje en la familia troncal española, ya casi desaparecida, que por carecer de patrimonio no puede «casar en casa», pero, por su alto linaje, no puede "casar fuera de casa») desarrollará una sexualidad «depredadora», seduciendo cualquier mujer (casada o soltera) a cambio también de favores o donaciones, estableciendo así un tipo de relación a medio camino entre la poliandria (si yace con mujer casada) y la prostitución (si lo hace con soltera).

Precisamente para evitar esta sexualidad depredadora, muchas ciudades medievales (cuando aún no se conocía la sífilis) disponían de burdeles municipales o los establecían en época de mercados, fiestas populares, torneos, cortes, peregrinaciones o romerías ${ }^{36}$.

3. ' La masturbación, como retirada a la autogratificación; así al menos parece sugerirlo la disminución «dramática» de delitos sexuales atestiguada por la policía de Copenhague cuando se liberalizó la venta de material pornográfico ${ }^{37}$. De ser esto así, la masturbación sería el sustituto universal de toda otra forma de sexualidad.

4. ${ }^{\mathrm{a}}$ Por supuesto, las dos formas extremas de adaptación son la castidad y la violencia sexual. En el primer caso se produce la retirada total, y en el segundo, la obtención ilegítima de lo que se niega por vías legítimas.

5. Finalmente, puede que surja la prostitución en alguna de sus muchas formas.

(al menos la de la hija que hereda), aunque no la promiscuidad. Así, en la Galicia rural, el régimen matriarcal se asemejaba a una poliandria sucesiva: cada mujer, fijada por el patrimonio en un lugar concreto, permitía el acceso sexual a los varones que por allí pasaban; todos los hijos llevarán el nombre del primer marido o del suyo propio, aunque sean hijos naturales de varios otros. A todos los efectos es como si ella, dueña y ama, tuviera varios maridos.

${ }_{36}$ Así, son conocidos los de Hamburgo, Viena y Augsburgo, donde las prostitutas constituían un gremio. Eran especialmente importantes en las ciudades universitarias (Padua, Florencia, París, Heidelberg, Oxford). En España, el primero que se creó fue en Salamanca, otorgado por los Reyes Católicos al Concejo el 13 de mayo de 1498. Pero, según B. Bennassar, en la España medieval «cada ciudad importante contaba con su prostíbulo, en ocasiones muy bien organizado»; era famoso, a principios del xvI, el de Valencia. Véanse Lewis Mumford, The Culture of Cities (Harcourt, Brace and Co., Nueva York), 1938, p. 35; voz «Prostitución», en Enciclopedia Universal Ilustrada (Espasa-Calpe), 1922, vol. 47, y B. Bennassar, Los Españoles (Argos, S. A., Barcelona), 1976, pp. 179 y ss., donde se describe el burdel municipal de Valencia en 1501. Para el de Salamanca, véase J. JuAnes, Los milagros y su gente (G. Cervantes, Salamanca), 1976.

${ }^{37}$ Citado por The Report of the Commission on Obscenity and Pornography (Holt, Rinehart and Winston, Nueva York), 1967, p. 31. EI análisis estadístico de los datos en relación con Estados Unidos mostró una situación menos nítida, con aumentos en algunos tipos delictivos (violación) y disminución en otros. 
Resumiendo, en el caso de que las condiciones antes señaladas no se den, habrá grupos de personas condenadas bien a la castidad, bien a algunos de los sustitutos de la relación sexual legítima, que de este modo se revelan como instituciones sociales, no sólo como perversiones o defectos de socialización ( $\mathrm{y}$ ello al margen de que también pueden ser esto). Es decir, cuando por razones demográficas o morales hay grupos de personas a las que se les niega el acceso a la relación heterosexual legítima y satisfactoria, aparecerán instituciones latentes (o no), en todo caso ilegítimas y amorales, como parte esencial del equilibrio social.

\subsection{Mercado sexual, mercado matrimonial y mercado de trabajo}

Hasta el momento hemos explicado las causas que pueden originar la demanda de prostitución (o de sus sustitutos), así como las que originan la oferta potencial de prostitutas; más concretamente, la oferta de favores sexuales por parte de las mujeres. Ahora bien, que estos favores sexuales femeninos devengan o no en prostitución es algo que depende de otras variables. Concretamente, es necesario que la soltera forzosa no tenga otras posibilidades de ganarse la vida o que, al menos, el coste de oportunidad de la prostitución compense el abandonar otras salidas profesionales.

En definitiva, el tema de la prostitución no puede analizarse relacionándolo sólo con la institución del matrimonio. En cuanto mercado de satisfacción de pulsiones sexuales en que se intercambia dinero por servicios profesionales, está directamente relacionada con dos mercados: el matrimonial, sin duda, pues el matrimonio satisfactorio ${ }^{38}$, como hemos visto, es sustituto funcional de la demanda de prostitución ${ }^{39}$ y elimina, además, la oferta potencial; pero también con el mercado de trabajo femenino, pues el trabajo de la mujer es sustituto funcional de la oferta de prostitución. Por ello, la prostitución será, sin duda, mayor allí donde se rigidifiquen estos dos mercados, es decir, donde y cuando sea más difícil conseguir bien marido o esposa, bien trabajo para la mujer (el caso de la prostitución masculina es más raro, sin duda, porque es raro que el varón no tenga salidas profesionales alternativas).

De ahí, por citar algún ejemplo, el enorme desarrollo de la prostitución en la Europa de la posguerra, donde, al déficit de varones causado por la

${ }^{38}$ Y quizás no sea inútil recordar que es típico de la cultura occidental moderna el concebir el matrimonio no como una alianza social, sino como el lugar donde amor romántico, cuidado de la prole y satisfacción sexual se realizan conjuntamente.

${ }^{39}$ Es conocido históricamente el caso de Virginia City (Nevada) entre 1860 y 1875 , donde, como consecuencia de la fiebre de la plata, las únicas mujeres que habitaban eran prostitutas que se encargaban de todos los papeles femeninos: cuidar a los enfermos, organizar la caridad pública, preparar fiestas y desfiles cívicos, etc. Pero a partir de 1870 comenzaron a llegar primero maestras, más tarde otras mujeres honestas y las prostitutas fueron de nuevo marginadas. Véase Marion Goldman, «Prostitution and Virtue in $\mathrm{Ne}$ vada», Society, noviembre-diciembre 1972, pp. 32-58. 
alta mortalidad de la guerra y la posguerra, se sumaba la total carencia de trabajo para las mujeres (muchas de ellas viudas de guerra). Vemos, pues, que el surgimiento de la prostitución femenina está ligado a numerosos factores demográficos y sociales que determinarán, además, si será la prostitución lo que surgirá u otro de sus sustitutos funcionales. Cuando, como ocurre en nuestras sociedades, la homosexualidad, el incesto y la poligamia son duramente condenados tanto por la ley como por la moral, y el trabajo de la mujer es difícil de conseguir, no es raro que la prostitución femenina florezca. Alli donde, por las razones que sean, se produzca un desequilibrio demográfico o social, aparecerán prostitutas.

En todo caso, es necesario distinguir entre las necesidades sistemáticas de prostitución y el modo de cubrir esas necesidades, es decir, las pautas de reclutamiento. Una sociedad puede producir demandas de prostitución en un lugar determinado de su estructura, demanda que será cubierta, sin embargo, por la oferta que se puede crear en otro lugar. Como dice Ivan Light, «la demanda no explica la oferta porque intervienen (además) la cultura de los proveedores, la organización social y la demografía» ${ }^{40}$.

Concretamente, si aumenta la soltería femenina en las ciudades (pongamos por caso) como consecuencia del déficit de varones, ello incrementará la competencia entre mujeres por conseguir los pocos varones existentes. La competencia se extenderá a lo largo de todo el sistema matrimonial y a todos los niveles sociales, de modo que al final quedarán solteras las mujeres del medio rural, menos atractivas y con menor o nulo patrimonio; ellas serán la nueva generación de prostitutas. En el mercado matrimonial, como en todo mercado, el objeto más valioso expulsa al menos valioso. Por ello, lo usual es que las prostitutas vengan del medio rural, pero ejerzan en medio urbano.

Un caso interesante se da cuando, como ocurre en las sociedades de frontera (el Oeste de los Estados Unidos hasta principio de siglo, Australia hasta hace pocos años), el déficit de mujeres era crónico. En tales condiciones, las mujeres adquieren un valor más alto, tanto en el mercado matrimonial (en el que podrán contraer matrimonio con varones más codiciados) como en el mercado sexual. Lo usual en tales condiciones es que el alto valor de la mujer, incluso de la prostituta profesional, elimine el estigma correspondiente.

Así, recogiendo el argumento tradicional acerca de la prostitución, ésta puede ser causada por rigideces en el sistema normativo que condenan a la virginidad y la soltería a numerosos hombres y mujeres; pero si esto puede originar una demanda de prostitución, también puede originarla de homosexualidad o de relaciones adúlteras o incestuosas o canalizarse hacia la masturbación. Por otro lado, para que haya no sólo demanda, sino también oferta real, es necesario que la prostitución no tenga sustituto funcional, cual

${ }^{40}$ I. LrgHT, op. cit., p. 1. 
es el trabajo femenino bien remunerado. Si nuestro modelo es adecuado, ello quiere decir - recogiendo el símil de K. Davis- que eliminar completamente la prostitución es tan mítico como conseguir el pleno empleo; rigideces inevitables a lo largo del sistema de intercambios sexuales ${ }^{41}$, o simples retrasos en el ajustamiento de todas las variables intervinientes, producirán un mínimo de prostitución en cualquier sociedad. Siempre habrá personas cuyas demandas sexuales difícilmente podrán encontrar salida en los canales legítimos, y siempre habrá personas dispuestas (o forzadas) a aprovechar tales oportunidades. Si, dadas tales condiciones, se cierran las salidas representadas por la prostitución, lo más probable es que se acuda a sus sustitutos funcionales.

\section{LA ESTRUCTURA SOCIAL DE LA AMBIVALENCIA MORAL}

Este análisis muestra hasta qué punto la ambivalencia sociológica puede explicar conductas que, en principio, aparecen atribuibles sólo a falta de moralidad. La prostituta es víctima de dos normas morales que, aparentemente, parecen reforzarse, pero que en su caso se contradicen. Por un lado, el deber de conservar la propia honestidad; por otro, la orientación general de la mujer hacia el matrimonio y no hacia el trabajo. La consecuencia de ambas es que, perdida la virtud, no tiene más salida que transformar su estigma en vocación, haciendo de la deshonestidad una profesión ( $o$, si se prefiere, del vicio, virtud). Del mismo modo, el varón que no tiene acceso legítimo a una mujer se encuentra en un dilema. Un hombre que no ejerce, no lo es; pero al tiempo no puede ejercer legítimamente. En estos y similares casos, la sociedad, sin saberlo, está sometiendo a algunas personas a mandatos contradictorios, y lo paradójico del caso es que es tal la fuerza de la cultura que los actores cumplen ambos mandatos, bien buscando una conducta alternativa que solucione el dilema, bien a través de una conducta oscilatoria.

\subsection{Segregación de audiencias y doble vida}

Ahora bien, esa conducta oscilante plantea serias dificultades al actor. Veamos el caso del joven que trata de cumplir con su rito de iniciación sexual. Por un lado, tiene que hacerlo para quedar bien ante sus amigos y él mismo; por otro lado, tiene que evitarlo para quedar bien ante la moral pública. La solución de compromiso es, evidentemente, ocultar ante los segundos aquello de lo que alardea ante los primeros, es decir, segregar lo más

${ }^{41}$ Rigideces sociales (aunque no conscientemente) reconocidas, que las agencias matrimoniales (hoy) o los bailes de sociedad, tés o fiestas organizadas por el párroco tratarán de eliminar al máximo. 
nítidamente posible las dos audiencias. Pero la segregación de audiencias puede traducirse en graves problemas personales. Así, la sociedad española ha tolerado la homosexualidad masculina siempre que ésta fuera discreta y privada, siendo, por el contrario, intolerante ante el «escándalo», como acepta para un casado «tirarse una cana al aire», pero no tener una amiga. El transgresor se ve entonces obligado a introducir el máximo de distancia social $^{42}$ entre ambos mundos para evitar que se produzca cualquier cortocircuito informativo. El concepto de «conexión informativa», tal y como lo define Goffman, es útil en este contexto:

«Dados los hechos sociales importantes de la vida de un individuo..., ¿cuál es el grado de proximidad o alejamiento que existe entre dos hechos cualesquiera, medible por la frecuencia con la cual aquellos que conocen uno de ellos pueden conocer también el otro? ${ }^{43}$.

En todo caso, la segregación de audiencias origina una separación tajante de dos contextos vitales: el público y aceptable, y el privado, de tal modo que cada uno no sepa nada del otro. Como escribió un homosexual:

«Estaba condenado a ser mentiroso, llevando una vida durante mis horas de trabajo y otra cuando era libre. Tenía dos grupos de amigos; casi, se podría decir, dos caras. $Y$ en el fondo de mi alma siempre un miedo persistente de que mis dos mundos pudieran súbitamente colisionar» ${ }^{44}$.

Pues tan importante para proteger la personalidad pública es evitar que la identidad secreta penetre en ese mundo como evitar que en el otro mundo se sepa acerca de su identidad pública. En caso contrario, el desviado se ve sometido a la amenaza perpetua de chantaje ${ }^{45}$ (frecuente entre los homosexuales vergonzantes y ejemplo típico de delincuencia secundaria, es decir, generada por la propia norma moral o penal).

${ }^{42}$ El concepto de distancia social, tal y como lo utilizamos aquí, distinto, por supuesto, del de distancia física, puede definirse - con PARK y BuRgess - como las probabilidades de acercamiento o de repulsión entre dos personas - Introduction to the Science of Sociology (University of Chicago Press, Chicago), 1924-. Bogardus elaboró una escala de intervalos libres para medirla, aplicándola sobre todo al racismo o la xenofobia. La escala comprendía los siguientes items: 1) contraer matrimonio (mínimo de distancia social); 2) aceptación en el propio club; 3) aceptación como vecino; 4) aceptación como miembro de la misma ocupación; 5) aceptación como compatriota; 6) aceptación como visitante o turista; 7) exclusión total. Véase Emory S. Bogardus, «The Measurement of Social Distance», en Newcomb y Hartley (eds.), Readings in Social Psychology (Henry Holt and Co., Nueva York), 1947, pp. 503 y ss. Lo típico, sin embargo, en el caso de la ambivalencia es que la distancia social es causada por la proximidad (en otro espacio-tiempo) y ésta sólo puede existir sobre la base de la distancia.

${ }_{43}$ E. Goffman, Estigma (Amorrortu, Buenos Aires), 1970, p. 80.

${ }^{44}$ Peter Wildeblood, Against the Law (Penguin Books, Londres), 1955, p. 37.

${ }^{45}$ Para un análisis de los diversos tipos de chantaje, véase GofFMAN, op. cit., pp. 94-95. 
Goffman ha señalado cómo, junto a la doble vida simple en que hay que distinguir a quienes creen conocer íntegramente al hombre de quienes realmente lo conocen, hay que señalar la doble vida doble cuando el desviado «se mueve en dos círculos, cada uno de los cuales desconoce la existencia del otro y posee la propia biografía del individuo ${ }^{46}$.

El desviado acaba por tener dos identidades públicas adecuadas para espacios, horas y audiencias definidas, de modo que su vida gira alrededor de una continua segregación de contextos sociales, al tiempo que él cruza cotidianamente los límites entre ambos. Pues, como dice Goffman, «existen estigmas importantes, tales como la prostitución, el robo, la homosexualidad, la mendicidad y la adicción a las drogas, que el individuo debe ocultar cuidadosamente ante determinada clase de personas - la policía - y exponer en forma sistemática ante otras: clientes, cómplices, enlaces, compradores de objetos robados» ${ }^{47}$.

Mantener dos mundos y dos personalidades tan nítidamente diferenciados como sea posible, al tiempo que encuentra el modo de escurrirse entre uno y otro, constituye una de las técnicas básicas del drogadicto, prostituta o homosexual vergonzante. El encubrimiento se irá produciendo poco a poco. Comenzará con un encubrimiento inconsciente para pasar a un encubrimiento semivoluntario, encubrimiento durante momentos no rutinarios de su vida social (un viaje o unas vacaciones) para pasar al encubrimiento en circunstancias rutinarias de la vida cotidiana, llegando finalmente a la desaparición.

«Se puede señalar que cuando se procura un encubrimiento relativamente total, el individuo organiza, a veces en forma consciente, su propio rite de passage: va a otra ciudad, se refugia en una habitación durante algunos días, con ropas y afeites seleccionados previamente, y después, como una mariposa, emerge para probar sus flamantes alas» ${ }^{48}$.

Esta segregación implica, claro está, que el propio desviado acepta la situación marginada de su mundo secreto. No sólo los profesionales, incluso los usuarios del mercado del vicio (y especialmente los usuarios) están interesados en segregar social y ecológicamente el mundo del vicio del honesto, lo que no hace sino traducir sociológicamente el dato de que ellos mismos aceptan, al menos externamente, la moralidad dominante. Así, pues, la marginación de la subcultura del vicio deriva no tanto de la presión policial o del intento de apartamiento de los honestos, sino también de elementales estrategias de ocultamiento de los usuarios. La conclusión paradójica de que

46 E. Goffman, op. cit., p. 96.

47 Goffman, op. cit., p. 91; también, T. Hirs h I, «The Professional Prostitute», Berkeley Journal of Sociology, VII (1962), p. 36.

${ }^{48}$ E. Goffman, op. cit., p. 98. 
sólo mezclando ambos mundos y eliminando la segregación existente se acabaría con la demanda de servicios ilegales es tan cierta como irrealizable, pues tan pronto como esto se hubiera conseguido la demanda social de vicio generaría una nueva oferta oculta.

Por otro lado, la segregación genera graves problemas psíquicos, por un lado, y territoriales, por otro. Pues, como dice Merton, la ambivalencia sociológica es una de las fuentes más importantes de la ambivalencia psíquica ${ }^{49}$ -y viceversa- Desde luego, en el caso de doble vida doble, el sujeto puede llegar a conseguir el encubrimiento total para todos..., para todos menos para él:

«Cuando se burlaban de los homosexuales tenía que reírme con los demás, y cuando la charla giraba alrededor de las mujeres debía inventar mis propias conquistas. En esos momentos me odiaba a mí mismo, pero, aparentemente, no podía hacer otra cosa. Toda mi vida se convirtió en una mentira» ${ }^{50}$.

«No he sabido, hasta acabar de escribir este artículo..., el grado de odio a mí mismo que mi homosexualidad ha implicado... De hecho, a lo largo de estos años, he aceptado ampliamente la definición social del homosexual como extraño (queer), pervertido, pecador» ${ }^{51}$.

$\mathrm{Y}$, así, la ambivalencia sociológica deviene ambivalencia psíquica:

«Dado que en nuestra sociedad el individuo estigmatizado adquiere estándares de identidad que aplica a sí mismo, a pesar de no poder adaptarse a ellos, es inevitable que sienta cierta ambivalencia respecto de su yo... En síntesis, no puede ni aceptar al grupo ni abandonarlo» ${ }^{52}$.

Esta situación de disonancia afectiva y autoagresividad sólo puede suprimirse a través del suicidio (y no es infrecuente que él mismo se delate para pagar su culpa satisfaciendo su autoagresividad) o de la disociación real entre dos personalidades; en el extremo nos encontraríamos con una doble personalidad que, como Dr. Jeckyll y Mr. Hyde, tienen siempre una parte pura y otra impura, una diurna y otra nocturna, una pública y otra secreta (madre honesta y prostituta; marido trabajador y violador asesino, etc.). En estos casos, el desviado acaba asumiendo las identidades que la sociedad le otorga, y puesto que ambas están socialmente disociadas, se disocian igualmente en su psiquismo. Cuanto mayor sea, por un lado, la necesidad de acudir a tales servicios inmorales $y$, por el otro, la necesidad de afirmar pú-

49 R. K. Merton, op. cit., p. 7.

${ }^{50}$ P. Wildeblood, Against the Law, op. cit., p. 32.

51 David McReynolds, «Notes for a More Coherent Article», en We bave been invaded by the 21st Century (Praeger Publishers, Nueva York), 1970, p. 131.

${ }^{52}$ E. Goffman, op. cit., pp. 127-128. 
blicamente lo que en privado se niega, mayor será el autoextrañamiento, sentimiento de culpa que el desviado vierte sobre sí mismo.

\subsection{Segregación espacial y temporal}

Ahora bien, del mismo modo que la ambivalencia sociológica se traduce en una conducta oscilante y, eventualmente, en doble personalidad, lo mismo ocurre en términos ecológicos.

Efectivamente, la marginación social se traduce en unas específicas pautas de establecimiento espacial, de distancia física o social. El vicio se compra y se vende en espacios funcionalmente especializados en este desconocido sector terciario: bares, calles, barrios, incluso ciudades enteras se especializan en la provisión de servicios ilegales, constituyendo así economías que, como la de la prostitución o la droga, tienen un peso económico gigantesco. Es más, cabe especular que una de las primeras áreas urbanas que se diferenciaron, ya en las más antiguas ciudades, es justamente la dedicada a la prostitución.

«Si la prostitución es o no la más antigua profesión del mundo, es digno de anotar que la especialización en el juego sexual hace su aparición bien temprano en los textos que hacen referencia a la vida urbana. Así, leemos que mientras "Gilgamesh atraía a los artesanos, los armeros", "Isthar congregaba" las mujeres de placer y las prostitutas del templo» ${ }^{53}$.

Las Vegas (juego), Reno (prostitución), Bangkok (droga), París son ejemplos conocidos. En la antigüedad lo fue Babilonia, como París durante el siglo xIx y Venecia en el xviri.

En casos extremos, la segregación se manifiesta (como en Hamburgo) palpablemente mediante vallas o acotamiento físico del espacio, dentro del cual se entra ya en ese otro mundo donde las vitrinas exhiben lo que sólo un paso más allá estaría prohibido. Y allí donde la segregación física no es palpable se percibe la segregación simbólica ${ }^{54}$ : el área se identifica al visi-

${ }_{53}$ Lewis Mumford, The City in History (Harcourt, Brace and Co., Nueva York), 1961, p. 105.

${ }_{54}$ Sobre la delimitación de las áreas naturales urbanas en función de su valor simbólico más que por su valor económico (como enfatizaban los ecólogos puros contra los ecólogos socioculturales), véase el texto clásico de W. Firey, Land Use in Central Boston (Harvard University Press), 1958. También, en el mismo sentido, R. E. Dickinson, The West European City (Routledge and Kegan Paul, Londres), 1951; G. E. Grunebaum, Islam, memoria de la American Anthropological Association, núm. 81, 1955. Con todo, hay que decir que en las ciudades americanas, sin tradición, las áreas del vicio (red light district) están determinadas, más que nada, por su valor económico: son sectores urbanos centrales (downtown), pero ligeramente descentrados en relación con el núcleo de oficinas 
tante a través de sus luces y escaparates; aunque, en este caso, la falta de acotamiento impone una específica estructura física: los locales atraen exteriormente por sus luces y colores vivos, pero están cerrados, carecen de ventanas o son opacas, están enclaustrados, en un juego de atracción externa y cierre fáctico que refleja el juego de la ambivalencia.

La segregación ecológica no es sólo espacial, sino también temporal. Del mismo modo que la persona que penetra en ellos se transforma en otra, mediante un rito de paso, toda el área o la ciudad por la mañana puede transformarse en barrio familiar o en una zona normal:

«El área de Boston donde ocurren muchos asaltos y peleas, en que la prostitución es explícita y los bares ofrecen go-go dancers, es llamado la "zona de combate"... Pero esta zona de combate no funciona más tarde de las 2,30 de la noche ni durante el día. Durante el día esa zona es parte del área de negocios. Numerosas personas van a tiendas, a los almacenes próximos o, de algún modo, pasan por allí y son clientes de los restaurantes y negocios que allí existen. Así, pues, la designación de zona de combate se refiere a tales lugares sólo durante ciertas horas...» ${ }^{55}$.

Todo el juego del transformismo se desvanece para renacer de nuevo por la noche: consumada la transgresión todo vuelve al orden, concentrando a los grupos estigmatizados en un «gbetto temporal» (M. Melbin) que se cierra sobre ellos y sus espacios. El resultado, como bien ha visto A. Sastre, es la desterritorialización de los profesionales del vicio: la marginación (o al menos cierto tipo de marginación) puede ser definida por ese carácter desterritorializado de aquellos a quienes afecta:

«Es el hombre invisible, cuya vida transcurre en un espacio que sólo tiene de común con el de los otros el que es el mismo... hasta cierto punto: es el mismo en cuanto mero soporte de distintos mundos, quizá adyacentes, pero desde luego absolutamente incomunicados. Entonces el mundo es relativamente el mismo y, al mismo tiempo, absolutamente otro" ${ }^{56}$.

y tiendas. En ciudades tradicionales (como en Europa), estos distritos se ubican en áreas históricamente definidas (según criterios varios, como puede ser fuera de las murallas, o al otro lado del río, o en zona de cuarteles, etc.). Sobre el simbolismo del espacio y el tiempo y los iconos urbanos, véase el sugerente artículo de Anselm L. STrauss, «Strategies for Discovering Urban Theory", en Leo D. ScHNORE (ed.), Social Science and the City (Praeger Publishers, Nueva York), 1969, pp. 79 y ss., que trata de ampliar las bases de su Images of the American City (Free Press, Nueva York), 1961.

"5 Véase Murray Melbin, "Night as Frontier», American Sociological Review, 43 (1978), pp. 12 y ss.

s6 A. SASTRE, Lumpen, marginación y jerigonza (Legasa, Madrid), 1980, pp. 111 y 322. 


\subsection{La incomunicación, el secreto y los lenguajes del bampa}

Esta profunda segregación social y física implica que la comunicación entre uno y otro grupo, entre el mundo del vicio y el del orden, está rota $o$, al menos, notoriamente distorsionada. Primero, porque oyentes pertenecientes a cada mundo tendrán imágenes públicas segmentadas y parciales del hablante $\mathrm{y}$, por lo tanto, interpretarán sus palabras de distinto modo. Dicho con mayor precisión, no es la comunicación, sino la metacomunicación, lo que está distorsionada. Pero, sobre todo, porque para cada mundo el otro es tabú; realidad literalmente aparte y separada, de la que no se habla.

«El Barrio salmantino -relata J. Juanes- era encuentro habitual de todos los salmantinos de todas las clases sociales y del campo. En épocas de duras discusiones políticas, los líderes de la provincia se combatían en cualquier lugar y, por supuesto, en la prensa, inculpándose de toda clase de frivolidades menos la de ir al barrio; era como un código espacial... una mafia blanca en la que implícitamente estaba inscrito todo el mundo a sabiendas de que nadie se extorsionaría por andar de picos pardos» ${ }^{57}$.

Se crea así una complicidad generalizada por la cual los justos pecadores se protegen entre sí contra la maledicencia pública (aunque, sin duda, no contra la privada, pues la información se difundirá igualmente en voz baja y tono confidencial). Esta complicidad de la que todo justo pecador participa crea entre ellos la posibilidad de un chantaje generalizado. Goffman comenta que «dada la abundancia de cosas que la gente oculta avergonzada, sorprende que el chantaje pleno no sea más frecuente» ${ }^{58}$. No hay nada sorprendente en ello: todos podrían chantajear a todos, pero ninguno está interesado en ello. Los del hampa podrían chantajear a los justos, pero arruinarían su negocio y serían perseguidos por el propio hampa por generar desconfianza; los justos podrían chantajearse entre sí, pero por ellos mismos no lo hacen; los justos, a su vez, podrían chantajear al hampa, pero ello, aparte de ser peligroso, les privaría de los servicios que les proporcionan. La complicidad generalizada y tácita de unos y otros es la mejor garantía contra el chantaje.

En todo caso, la complicidad es, evidentemente, tácita, pues, como muestra J. Juanes, de eso «no se habla». El no se habla quiere decir varias cosas más. En primer lugar, que no hay verdadera comunicación entre el mundo marginado de los profesionales y usuarios del vicio y el mundo honesto. De ahí la paradójica situación del mundo del vicio: tiene que estar abierto como cual. quier negocio, pero también tiene que estar cerrado por razones de decoro,

57 J. JUANES, op. cit., p. 60.

${ }^{58}$ E. GoffMan, op. cit., p. 95. 
decencia y protección; tiene que pasar inadvertido, pero al tiempo debe ser públicamente conocido ${ }^{59}$.

Esta segregación comunicativa del hampa puede llegar a ser tal que origine su propio lenguaje, evitando así que conversaciones embarazosas puedan llegar a oídos de sujetos poco recomendables. R. Salillas nos informa que el germanias, antiguo lenguaje del hampa española, se generó en la cárcel de Sevilla cuando esta ciudad era un centro comercial, allá por el siglo xvi; el germanias o jerigonza se mezcló más tarde, a lo largo del xIx, con el caló, conservado por los gitanos. Esta fusión de argots delincuentes, bastante frecuente, da pie a Alfonso Sastre para sostener la tesis del internacionalismo de las jergas: se hablan entre ellos y, así, sus lenguas se mezclan; no hablan a los justos $\mathrm{y}$, por ello, sus lenguas no se mezclan; mantienen también las distancias, y sólo palabras sueltas alcanzan a veces el honor de ser legitimadas por el habla oficial. Casi todos los argots conocidos tienen el mismo origen: hablas de grupos cuya vida es peligrosa, que tienen que ocultarse para vivir, pero que también tienen que comunicar entre ellos. Así, el mismo argot de los delincuentes franceses, el cant o slang de los ingleses, el lunfardo (de lunfa $=$ preso) de Argentina, la cobertanza de Cerdeña, el actual habla de las cárceles españolas, el taleguero; pero también hablas de grupos u oficios marginados: el merchero, habla de los quinquis, el bron de los leñadores asturianos, la gaceria de los trilleros segovianos, el barellete de los afiladores, la garisma de los ciegos. «Lenguajes bastardos", los llamaba Salinas, que, al decir de Víctor Hugo, «quieren decirlo todo y ocultarlo todo». Lengua «desterritorializada», dice A. Sastre, que se habla literalmente en ningún sitio, un habla que trata de ocultarse a sí misma, comunicar sin ser oída, a medio camino entre el silencio y la interjección, necesariamente metafórica, y para la que es una afrenta nombrar las cosas por su propio nombre ${ }^{60}$.

$\mathrm{La}$ incomunicación entre el mundo de los marginados y el honesto se ve, así, institucionalizada en la propia lengua. Son propiamente otras perso-

59 De ahí la existencia de guías secretas sobre el mundo prostibulario y del mercado sexual, hoy prácticamente legitimadas. Recordemos, en este sentido, que El arte de las putas, de Leandro FERNÁNDEZ DE MORATín (circa 1777), era una guía secreta del Madrid del xviri. A. Popof, en el prólogo de una edición reciente (Premia Editores, México, 1978), nos informa de otras guías secretas más antiguas conservadas en la Biblioteca Nacional de París: La tariffa della puttane di Venezia (siglo xvI) y La rettorica delle puttane (siglo XVII).

${ }_{60}$ Sin duda, el mejor libro que conozco sobre este tema (y del que he citado en este último párrafo sin reparos) es el de A. SASTRE, Lumpen, marginación y jerigonza (Legasa, Madrid), 1980. Aparte, la aportación pionera en este terreno la efectuó Rafael SAlillas, interesante y poco conocido criminólogo español de principio de siglo que, desde su posición privilegiada de director de la cárcel de Madrid, se interesó por el tema; véase su obra El delincuente español. El Lenguaje (Victoriano Suárez, Madrid), 1896. Pueden citarse las Poesias Germanescas, editadas por John M. HrLl (Indiana University, Blooming. ton), 1945; el Diccionario Caló-Castellano, de Francisco Quindale (Oficina Topográfica del Hospicio, Madrid), 1867, y Barsaly Dávila y Blas PÉrez, Apuntes del dialecto caló o gitano puro (Diana Artes Gráficas, Madrid), 1943. 
nas, provenientes de ninguna parte, apátridas, sin nación y sin pueblo, con una lengua prestada para mejor ocultarse. Pero la incomunicación, que el argot no hace sino reforzar, otorga siempre una sensación de irrealidad a aquello sobre lo que se cierne. Real es lo que se nos resiste, decía Maine de Biran, pero él nos alude aquí a la pluralidad de la resistencia: se resiste para todos. Aquello sobre lo que se cierne el velo del silencio es realidad aparte y separada, sin existencia pública. Esto acaba otorgando al mundo del vicio (para todos menos para sus profesionales) una profunda irrealidad. El vicio existe como algo latente, oculto, secreto; sus espacios y sus personas carecen de realidad pública y cuando emergen lo hacen como escándalo, como algo que no debiera existir. Penetrar en tales contextos es así, para el usuario, penetrar en un contexto onírico de realidades primordiales, fuera del orden rutinario, cotidiano y categorizado. Tal es, por lo demás, lo que ese mundo quiere ser: un contexto onírico para la realización simbólica de suenos, donde lo imposible y extraordinario tiene que ser posible. La nocturnidad, las luces y las sombras, el transformismo, el ocultamiento y el secreto, todo ello contribuye a hacer del espacio social del vicio un teatro de sombras en que cada uno representa los papeles que sus sueños le asignan. Tanto más onírico y más seductor cuanto mayor sea la segregación, la incomunicación y el enclaustramiento. Pues lo que en ese mundo se compra y se vende son sueños.

Gigantesco mercado de sueños comparable quizás sólo a ese otro mercado de sueños y delirios: el de la religión organizada. La religión une y socializa; el vicio separa, rompe. Pero ambos son capaces de estructurar una multitud y hacer de ella sociedad.

Una similitud que no debiera sorprender si recordamos, por ejemplo, que las prostitutas comenzaron su larga profesionalización como sacerdotisas de diosas femeninas; que los homosexuales (como los locos) son considerados en muchas culturas personas tocadas por los dioses; que las drogas, finalmente, han sido siempre, hasta su actual secularización (si es que tal cosa se está produciendo), ritos sagrados de aproximación a los dioses, a los misterios o a lo arcano. Pues, en definitiva, todo lo extraordinario es sagrado, bien divino, bien demoníaco.

Creemos que esta fenomenología de lo inmoral habrá servido, al ménos; para poner de manifiesto su complejidad. La ambivalencia sociológica hemos visto que se estructura doblemente: en términos psíquicos y en términos espacio-temporales. La fuerza que pueda tener el mundo del vicio dependerá, a su vez, del grado de institucionalización de la segregación; concretamente, será mayor cuanto mayor sean los tres factores que definen la ambivalencia: 
1. La disociación entre la teoría moral y los medios prácticos de realizarla.

2. El grado de afirmación pública colectiva que tenga esa moral.

3. El nivel de práctica inmoral.

El primer factor genera la ambivalencia; los otros dos simplemente la agudizan. Por otro lado, esto muestra la energía que lo inmoral y demoníaco es capaz de generar. En todo caso, la inmoralidad puede ser un factor de organización social eficaz, de modo que lo que como sociólogos debe interesarnos es no sólo una de las caras de la sociedad, ni siquiera una y después otra (pues ello reproduce la hipocresía socialmente estructurada), sino precisamente el juego interactivo de ambos aspectos: cómo lo moral deviene y/o refuerza lo inmoral, y viceversa. Del mismo modo que los impulsos morales de autorrepresión devienen agresión contra el otro transgresor, los impulsos morales socialmente establecidos generan vicio y éste, a su vez, moralidad. Es la contradicción entre fines morales, o de éstos con las posibilidades prácticas a realizarlos (posibilidades que están desigualmente distribuidas), lo que origina inmoralidad, condenando a grupos sociales a ser reclutados para el mundo del vicio; por otro lado, este mundo, por su propia existencia, y más aún cuando se sanciona (social o legalmente) al transgresor, refuerza la conciencia moral de la comunidad.

Ahora bien, gran parte de la fascinación y seducción del vicio deriva de que es una realidad aparte, separada, segregada y prohibida. Está prohibido porque se desea, pero se desea porque está prohibido. Y la fascinación de lo prohibido aumenta con la gravedad del castigo. Por ello, lo que es un mero círculo entre vicio y virtud puede transformarse, literalmente, en un círculo vicioso amplificado. Cuanto mayor es la sanción, mayor la segregación y mayor, también, el poder de seducción que ese mundo despliega.

\subsection{Transgresión y placer}

El problema fundamental del vicio, tal y como lo concebimos aquí, es el siguiente ( $y$ esto es también una definición tácita del mismo): ¿a qué se debe la unión intima entre la transgresión y el desencadenamiento del placer? Entiéndase, no digo que toda transgresión produce placer, ni menos aún que todo placer deriva de la transgresión; decimos que, en el caso de las conductas viciosas, la fascinación que pueden ejercer deriva, en gran medida, de que implican transgresión. El misterio del vicio radica precisamente en eso: que el asesino obtiene placer en ello y mata para satisfacerse; o el yonqui obtiene de su vida miserable, de su autodestrucción, una enorme satisfacción. De ahí el carácter radicalmente expresivo y simbólico de tales conductas, que no sólo no son medio para un fin más allá de ellas, sino que ni siquiera 
ellas son necesarias, pues casi lo único necesario es la transgresión; todo yonqui podría llevar una vida cómoda limitando su necesidad de droga y trabajando para poder pagarla, pero no es eso lo que busca; quiere llegar al punto en que la droga rompe con su mundo cotidiano.

La respuesta a este tema puede formularse de muchos modos. Diremos, en primer lugar, lo que no es una respuesta suficiente: no lo es el dato del peligro que acompaña esas conductas. El peligro físico produce una intensa excitación, y así, un sentimiento de satisfacción enormemente placentero: lo han sentido los soldados en guerra, como lo sienten los cazadores, o los escaladores, o los espeleólogos, etc. Podría pensarse que el placer unido a la transgresión deriva del peligro, si no físico, sí social, sobredeterminando las conductas viciosas.

Sin duda, muchas de ellas tienen tal componente: las descripciones que hace Thomas de Quincey en Del asesinato considerado como una de las bellas artes muestran esa intensa sensación, al tiempo, de vitalidad y fortaleza, de poder, pero también de irrealidad temporal y espacial, que acompañan al momento del asesinato. Instante fatal que, como todos los momentos de peligro de muerte, se halla suspendido fuera del espacio y del tiempo, literalmente utópico y ucrónico y, por lo tanto, eterno, infinito y autosuficiente ${ }^{61}$. Los segundos son horas o las horas minutos, según el ritmo biológico que la sobreexcitación impone al organismo. El sujeto percibe la realidad con una lucidez y claridad extraordinarias, y es, sin duda alguna, esa agudeza perceptiva y la consiguiente rapidez de la respuesta motora, prácticamente instintiva, lo que comprime la sensación del tiempo ${ }^{62}$. El peligro de ser descubierto, el ataque repentino de la víctima, la intensidad que produce el escapar de la red tendida por la policía, el ser más astuto y hábil sorteando los peligros, todo ello contribuye a intensificar hasta el paroxismo una rara sensación de placer de la que todos participamos, por ejemplo, bajo la forma de novelas «negras». En ellas, el momento catártico del crimen como ruptura radical del orden ( «no matarás» es el primer mandamiento social) es la puerta que hace entrar al lector en el mundo del peligro y la persecución,

${ }^{61}$ «El asesinato - dice acertadamente Luis Loyza en su presentación del libro de De Quincey- es una transgresión mágica que suspende el tiempo y crea un mundo diabólico», un mundo de «tensión casi insoportable». Los dos golpes en la puerta que se escuchan en Macbeth, después del vil asesinato de Duncan, marcan, según De Quincey, ese horror que hace patente «la retirada del corazón humano y el ingreso del corazón diabólico». «Ha surgido otro mundo - continúa De Quincey-... el mundo de la vida cotidiana se ha detenido súbitamente, duerme, entra en trance... todo ha de caer ensimismado en un hondo síncope y suspensión de la pasión terrestre.» Un momento que «transfigura» a Macbeth. Para hacer patente el surgimiento de ese mundo, Shakespeare, intuitivamente, dispuso esos dos sonoros golpes que recuerdan esos otros golpes que aterraron a Don Juan, preludio también de la llegada de lo infernal. Véase Th. DE QUINCEY, op. cit. (Barral, Barcelona), 1974, pp. 10-11 y 135-136.

${ }_{62}$ «Lo extraordinario - dice Luis Loyza en su presentación del libro de De Quinceyes la alianza de un ambiente fantástico, de pesadilla, con ciertos detalles muy nítidos y precisos.» 
donde todo es posible y del que sólo puede salirse a través de la reconstrucción judicial del asesinato o (lo que es lo mismo, como en las novelas de Ross MacDonald) a través de la anamnesis del momento reprimido y olvidado en que se desató la violencia; el tiempo irreal se desvanece a través de la reconstrucción racional del crimen, al tiempo explicitación y codificación de la transgresión. Sin duda, esto no explica por qué el placer se escribe bajo el código de la transgresión, pero sí explica que quien haya sentido alguna vez esa sobreexcitación trate de encontrarla de nuevo, precisamente a través del peligro. Este sería una droga que estimularía la intensidad de la sensación y la transgresión y, así, la intensidad del placer.

Con todo, no debemos olvidar que muchas de las conductas viciosas no son peligrosas en el sentido físico. Todas ellas, desde luego, en cuanto rupturas del orden ético-moral, implican un riesgo de exclusión social, encarcelamiento, violencia defensiva de la sociedad o, en el mejor de los casos, de ostracismo, estigmatización o degradación pública. Pero incluso el asesinato practicado por mero placer, por ejemplo, es sin duda seguro y enormemente difícil de detectar, precisamente por su falta de móvil específico: se mata a una persona como podría matarse a cualquiera otra, y de ahí la dificultad de descubrir al culpable. Y éste sería uno de los casos más visibles, pues, en general, el vicio es solitario y se desarrolla en espacios privados, entre personas que consienten y que mantienen una ley de silencio que los protege a todos. En estos casos, la conexión entre transgresión y placer aparece casi libre de la influencia del peligro. ¿Por qué, pues, esa conexión?

Una primera respuesta está en la irrealidad del acto transgresor. Ese momento adquiere su fuerza por estar fuera del tiempo y del espacio. Suspensión espacio-temporal que consigue la transgresión por su propia naturaleza: fuera del orden social, el tiempo-espacio cotidiano se desvanece y se entra en el terreno primitivo de las sensaciones primordiales e infantiles, de las percepciones tal y como eran antes de devenir rutina, antes de ser ordenadas y categorizadas, de aprender a experimentarlas del modo socialmente definidas. La realidad se percibe entonces precategóricamente, caótica y desordenada, plena e intensa.

Pero la transgresión devuelve al hombre a la experiencia infantil en otro sentido más. Estar fuera del orden social significa no sólo salir más allá (o, mejor, más acá) de las estructuras cognitivas que definen socialmente el mundo real, sino también más acá de los deberes y responsabilidades socialmente impuestos. La transgresión lleva al sujeto al mundo de la irresponsabilidad, no de la inmoralidad, sino de la amoralidad, mundo infantil por excelencia. Y sólo ahí, liberado de toda culpabilidad en ese instante suspendido, el placer se desencadena libremente. De ahí la ambigüedad absoluta de la transgresión, que, en cuanto ruptura del orden moral, libera el placer al introducir al actor en un medio donde el deber ha desaparecido. El acto transgresor abre para el sujeto un mundo amoral. 
La antropología y la historia social nos muestran, por otro lado, que esa conexión entre ruptura normativa y placer ha sido utilizada por numerosas culturas, pero sin que ello diera lugar al ocultamiento y secreto propio del vicio. Los ritos orgiásticos o dionisíacos, los saturnales, los carnavales, las fiestas, suponían precisamente una ruptura institucionalizada de las normas sociales, asociadas siempre a conductas placenteras; en tales ocasiones, el despilfarro y el desprecio por las normas controladoras de la bebida, la comida, el vestido, la conducta sexual, las. jerarquías sociales o las deferencias, incluso el control de los excrementos, eran abolidas; tiempo de fiesta y despilfarro, un tiempo irreal, literalmente extraordinario, donde la sociedad rompe su orden cotidiano, deroga la vigencia del código moral y permite la satisfacción inmediata de los deseos. El tiempo de fiesta es por ello, también, tiempo de violencia, de muerte y de agresividad, pues, abolidas las normas cotidianas, el desorden no sólo favorece el conflicto, sino (lo que es más importante) libera la pulsión agresiva. Amor y muerte emergen entonces como impulsos arcaicos que engloban la última sabiduría del cuerpo, allí donde la cultura pierde su fuerza, bien porque una convención tradicional así lo establece, bien por cualquier otra razón: tiempos de guerra, sociedades de frontera, etc. Más allá del espacio-tiempo controlado por el orden social, los humanos se entienden entre sí y con el mundo en términos de amor y odio ${ }^{63}$.

Es sabido que estos ritos orgiásticos fortalecen el orden social. La liberación periódica y (lo que es más importante) institucionalizada de tales pulsiones libera de tensiones el cuerpo social y, tras la catarsis, viene la saciedad y el intimo deseo de un orden renovado. La mañana siguiente a la fiesta, el sentimiento de culpa por las atrocidades cometidas el día anterior fortalece la misma norma que alli, con tanta intensidad, fue ultrajada. La institucionalización ritual de la fiesta garantiza la propia supervivencia flexible, destensada, del orden social, elimina la sensación de rigidez y encorsetamiento, la eventual conciencia de la contrainte, haciendo desear aquello que por un momento se rechazó: el orden cotidiano del trabajo y el cumplimiento ritual por cada una de sus obligaciones. Del mismo modo, la transgresión secreta y personal no sólo no anula la norma, sino que obtiene su fuerza e intensidad del hecho de que la viola respetándola; quizás no haya un instante en que la norma tenga mayor fuerza que aquel en que es violada. Como decía Bataille,

${ }^{63}$ Lo mismo que en la fiesta ocurre actualmente durante las horas nocturnas en las ciudades, horas que definen la última frontera de Occidente, reducto al margen del orden cotidiano. "Por la noche la gente está muy atenta a los extraños cuando se cruzan en la calle. Cada uno de ellos trata de evaluat si el otro es potencialmente peligroso. Una vez decidido que el otro merece confianza, el sentimiento propio cambia de la actitud vigilante a la expansiva. Si no es enemigo, entonces es amigo.» Véase Murray Melbin, Night as Frontier, op. cit., p. 13. 
«la transgresión organizada forma, con el interdicto, un conjunto que define la vida social. La frecuencia - y la regularidad- de las transgresiones no invalida ella misma la firmeza intangible del interdicto, del que ella es siempre el complemento separado» ${ }^{64}$.

Como en el animismo psíquico, también la conciencia colectiva mantiene la ambivalencia fundamental en relación con sus prescripciones: cuanto más rígidas son, cuanto mayor es el peligro que representan para el sujeto, mayor fascinación ejercen y el deseo se alimenta del temor a perderse; pero precisamente porque el deseo está cargado de temor, él mismo atestigua de la aceptación del interdicto.

Este mecanismo revela algo terriblemente importante: el deseo puede extraer su fuerza precisamente del interdicto que lo inhibe. Al tocar el objeto tabú, el sujeto experimenta un placer intenso que extrae su fuerza de la misma prohibición, parásita ésta, y así la culpa deviene placer. Este es el mecanismo oculto: el placer se escribe bajo el código de la transgresión porque el placer es aquí culpabilidad sublimada.

De ahí que cuanto mayor sea la intensidad del sentimiento de culpa generado por la transgresión del interdicto, mayor es también la fuerza del placer, pues éste no es sino la culpa que se libera en ese momento suspendido más allá del orden moral.

Ahora bien, tales rituales colectivos y públicos de transgresión han desaparecido lentamente de la cultura occidental. Freud recordaba, en 1913, que los salvajes de las islas Fidji «conocen orgías sagradas en el curso de las cuales realizan precisamente las uniones sexuales más estrictamente prohibidas» ${ }^{65}$, cultos que se conservaron en el Mediterráneo en rituales religiosos dionisíacos o báquicos. Pero el cristianismo hizo mucho por controlarlos, racionalizando la conducta, estigmatizando la orgía y reconvirtiendo la fiesta corporal de la trangresión en un ritual simbólico de afirmación sagrada del orden. La liberación de la pulsión corporal, del deseo, era sublimada en la misa a través de la afirmación comunitaria del Orden Sagrado y el sacrificio e ingestión ritual del cuerpo y sangre del Padre, fantásticamente transustancializado. La fusión de los cuerpos, la bebida y comida despilfarrada, se traduce en una ordenada y uniformada agrupación de los fieles en el lugar sagrado, un racionalizado (y ya no sensible) milagro, desapareciendo la sensación de tiempo y espacio onírico que acompaña la fiesta.

Incluso eso es eliminado por el ascetismo intramundano protestante. Tiempo para descansar y preparar el cuerpo y el espíritu para la continuación del trabajo meticuloso e incesante, la fiesta desaparece en la cultura industrial moderna. El domingo se reproduce al cuerpo para el trabajo semanal. Sus sustitutos (el party, el cocktail, el baile) son tiempo para la constitución

${ }^{64}$ G. Bataille, El erotismo (Tusquets, Barcelona), 1979.

${ }^{65}$ S. FREUD, op. cit., p. 19. 
de una futura familia, la transmisión de información, la mutua socialización y control, y todo ello bajo el signo de la total desaparición de la violencia y la agresividad, del peligro por tanto, y con una mínima fusión corporal. El hacinamiento recuerda vagamente el sentido de la orgía, y sólo la borrachera conserva algo de la vieja catarsis. En definitiva, al tiempo que la transgresión física y real deviene simbólica, la afirmación simbólica del orden deviene real y concreta. El juego de lo latente-manifiesto se invierte, y la ruptura deviene latencia, significando oculto y no vivido, de tal modo que la catarsis desaparece. La fiesta acaba siendo puro cumplimiento ritual de deberes ordinarios, en ocasiones extraordinarios. La clave de la sensación de fiesta, el todo es posible, es absorbida en su pura racionalización e instrumentalización social.

Pero la desaparición de la catarsis se produce en una sociedad que ha exacerbado el orden social hasta transformarlo en una gigantesca máquina burocrática. La vida cotidiana se reproduce diariamente, sometida a unos ritmos perfectamente domesticados y previsibles, con una precisión cronológica regimentada y casi cuartelaria. No hay sociedad conocida en la historia de la humanidad que haya conseguido controlar la fuerza vital de sus miembros como la nuestra, poniéndola al servicio de un trabajo sencillamente compulsivo. Como un gigantesco hormiguero, los hombres de las sociedades industriales modernas repiten diariamente los mismos o parecidos gestos, hablan con las mismas o parecidas personas, en las mismas oficinas, restaurantes y calles. Este altísimo grado de previsibilidad de la conducta supone una poderosa burocratización de la vida social (al menos de la diurna), tal que se sabe casi en cada momento dónde está cada persona, lo que hace e incluso lo que hará en el futuro. De ahí la posibilidad de prever, con mayor o menor acierto, pero en todo caso con notable grado de certeza, la dinámica de la sociedad en muchos de sus aspectos. Es preciso comprender en toda su radicalidad y excepcionalidad el terrible esfuerzo de cumplimiento ritual de los deberes cotidianos que los ciudadanos de esta cultura realizan día a día, el gigantesco autocontrol que ello implica, el nivel casi inhumano de ascetismo intramundano que marca nuestra existencia, por debajo y más allá del brillo del consumo o del ocio.

No se eliminan sólo las catarsis colectivas ritualizadas, sino eventualmente incluso las espirituales, pues junto con la desaparición del tiempo orgiástico, igualmente desaparecen los espacios no controlados. En 1890, el Bureau of Census americano anunció que la tierra de frontera americana había llegado a su fin; los últimos pioneros habían alcanzado el mar. La desaparición del último gran limes supuso, junto con el fin de las grandes emigraciones intercontinentales, la ocupación y racionalización del espacio propio de todos aquellos socialmente más adaptados, aventureros, criminales, iluminados, místicos, miserables, etc. Todos los desheredados de este mundo tuvieron que some- 
terse, y sólo la noche conserva aún un recuerdo del misterio de la frontera ${ }^{66}$.

El orden se reproduce linealmente con una sorprendente monotonía, al tiempo que es sometido a un ritmo acelerado de cambio social planificado y gestionado. Las pulsiones más profundas tienen que ser perpetuamente sublimadas, pues en esta cultura no hay sitio para la transgresión y la agresividad tiene necesariamente que volcarse hacia el trabajo, el perpetuo ascenso en la infinita jerarquía social, el consumo.

La presión del orden cotidiano sobre el deseo de satisfacción corporal inmediata es tal, tanta es la fuerza de la coraza del carácter (esa jaula de bierro - Weber- que nos atenaza), que el placer se traslada hacia los elementos más arcaicos de la conciencia y se codifica bajo el signo de la transgresión. La transgresión "per se», en cuanto liberación del pesado orden cotidiano, es de por sí placentera. $\mathrm{Y}$, así, su sentido viene dado por todo aquello que queda más allá de la conciencia, más allá del cerebro socializado; placer y muerte se mezclan en esas oscuras regiones del inconsciente constantemente ocultas y controladas.

Esa es la respuesta a la pregunta de por qué el placer se escribe bajo el código de la transgresión. Por el doble proceso histórico de domesticación del desorden catártico y la institucionalización y racionalización de la vida cotidiana. Cuanto mayor es la sobresocialización del sujeto, su integración en el orden, mayor es también la fascinación que sobre él ejerce la transgresión de lo más básico de dicho orden: la identidad sexual, el cuerpo sagrado del otro, el sentimiento de autoconservación (que desaparece en los yonquis o los que juegan eróticamente a la ruleta rusa), la limpieza. La fascinación por el territorio urbano degradado y la suciedad, ese inframundo, es la revancha que se toman el placer y la muerte, sublimados a través de la transgresión.

Un trabajo de Eugenio Trías sobre la estética contemporánea ${ }^{67}$ puede quizás ayudarnos a desentrañar ese denso misterio del vicio, la transgresión y el placer. Decíamos que, en este campo, lo peculiar de la dinámica libidinal es que el placer extrae su intensidad del mismo sentimiento de culpa, fundiéndose así con su contrario y poniéndolo a su servicio. La represión otorga su poder al placer y éste se inscribe entonces bajo el código de la transgresión.

La tesis defendida por Trías parte de dos bellas citas. La primera, de Rainer María Rilke, afirma que «lo bello es el comienzo de lo terrible que todavía podemos soportar». La segunda, de Schelling, casi el negativo de la anterior, dice que «lo siniestro es aquello que, debiendo permanecer oculto, se ha revelado". La tesis de Trías es que la sensación estética se produce en el límite entre lo bello y lo siniestro, ahí donde lo uno no ha llegado aún a ser lo otro. La sensación estética salta donde el conocimiento penetra en terreno misterioso y terrible sin estar aún atemorizado, sino, al contrario,

- Véase el sugestivo trabajo de Murray Melbin, Nigbt as Frontier, ya citado.

"7 E. Trías, «Lo bello y lo siniestro», Revista de Occidente, 59 (1982), pp. 40 y ss. 
siendo capaz de comprender y asimilar el misterio. Por ello, «lo bello, sin referencia (metonímica) a lo siniestro, carece de fuerza y vitalidad para poder ser bello», pues la vitalidad del sentimiento estético se produce al contacto con ese más allá aún no revelado. Lo siniestro es parasitado por lo bello y puesto a su servicio; ése sería el secreto del artista.

Quizás no se ha afirmado suficientemente en sociología la importancia radical de los sentimientos y de la educación estética del hombre. Sólo Marcuse, al final de su crítica negativa del presente, llegó al claro convencimiento de que el cambio radical es un cambio en la percepción estética. Los hombres no nos movemos por mandatos éticos y menos por normas sociales interiorizadas; eso no es más que la parte visible de un edificio cuya base previa es el sentimiento educado de lo bello y del placer. Carecemos, sin embargo, de instrumental analítico para penetrar esa socialización sentimental y afectiva, base de todas las demás. En todo caso, las pulsiones más fuertes surgen en ese terreno aún precategórico de los sentimientos.

Pues lo que Trías está afirmando es, simplemente, que el placer se genera al contacto con lo siniestro, al contacto con lo terrible, con lo que puede destruirnos. En términos psicoanalíticos, diríamos que Eros se agudiza al contacto con la muerte, en el juego de ocultamiento y revelación de Thanatos. La muerte está presente en su ausencia, y es esta presencia ambivalente, próxima y lejana, de la muerte, la destrucción y el terror, ese miedo que se siente pero que aún se controla, esa sensación de pérdida irremisible, de abandono y caída, pero que se sabe mera sensación, lo que en tal instante se transmuta en su opuesto, se pone al servicio del placer y le hace estallar.

De modo similar, el vicio es la búsqueda compulsiva de ese instante en que el placer se carga de rechazo sin aún provocarlo, un arte negativo puesto bajo el signo de la impureza, una sublimación hacia abajo, hacia lo rechazado y expulsado. Por ello es un lenguaje más que, una conducta; símbolos socialmente construidos que apuntan a lo siniestro, pero sin que ello esté presente.

Es por ello un fenómeno urbano, industrial y contemporáneo, que no hubiera podido surgir en una sociedad como la medieval; en que «todas las cosas de la vida sufrían una cruel y orgullosa publicidad» (Huizinga). Pues sólo la disociación privado-público crea esa interiorización de la conciencia en cuyo fondo late lo reprimido, que, más allá de los límites del orden (sean éstos la propia conciencia o la frontera), está al acecho. Los oscuros objetos del deseo se fortalecen en la nueva frontera de la noche urbana y toman posesión de la ciudad como en una revancha cotidiana. Los ángeles de la noche, excluidos del orden, no se ven obligados a aceptarlo. Sin posibilidad de sublimación afloran en ellos las pulsiones que el justo, oscuramente, encierra en los sótanos de su alma. El desorden es la cara oculta, el precio pulsional del violento orden cotidiano. 